\title{
Activation of ROP6 GTPase by Phosphatidylglycerol in Arabidopsis
}

\author{
Xiuli Han, Yue Shi, Guoyong Liu, Yan Guo and Yongqing Yang* \\ State Key Laboratory of Plant Physiology and Biochemistry, College of Biological Sciences, China Agricultural University, \\ Beijing, China
}

OPEN ACCESS

Edited by:

Martin Huelskamp,

Universität zu Köln, Germany

Reviewed by:

Jianwei Pan

Lanzhou University, China Huifen Zhu

Capital Normal University, China

*Correspondence: Yongqing Yang yangyongqing@cau.edu.cn

Specialty section: This article was submitted to Plant Cell Biology,

a section of the journal

Frontiers in Plant Science

Received: 31 August 2017 Accepted: 01 March 2018 Published: 15 March 2018

Citation:

Han X, Shi Y, Liu G, Guo Y and Yang $Y$ (2018) Activation of ROP6 GTPase by Phosphatidylglycerol in Arabidopsis.

Front. Plant Sci. 9:347. doi: 10.3389/fpls.2018.00347
Plant Rho-like GTPases (ROPs) are switch-like proteins which play essential roles in controlling cell polarity development and cellular activities. ROPs are regulated by many factors, such as auxin, light, and RopGEFs and RopGAPs proteins. However, it has not been reported yet whether small molecules play a role in the regulation of ROP activity. Here, we showed that AtROP6 specially bound to a phospholipid, phosphatidylglycerol (PG), by the protein-lipid overlay and liposome sedimentation assays, and further MST assay gave a dissociation constant $(\mathrm{Kd})$ of $4.8 \pm 0.4 \mu \mathrm{M}$ for binding of $\mathrm{PG}$ to His-AtROP6. PG profile analysis in Arabidopsis revealed that PG existed both in leaves and roots but with distinctive fatty acyl chain patterns. By evaluating AtROP6 activity using RIC1 effector binding-based assay, we found that PG stimulated AtROP6 activity. In the FM4-64 uptake experiment, PG inhibited AtROP6-mediated endocytosis process. By evaluating internalization of PIN2, PG was shown to regulate endocytosis process coordinately with NAA. Further root gravitropism experiment revealed that PG enhanced the AtROP6-mediated root gravity response. These results suggest that the phospholipid PG physically binds AtROP6, stimulates its activity and influences AtROP6-mediated root gravity response in Arabidopsis.

Keywords: GTPase, ROP6, Phosphatidylglycerol, Arabidopsis, Activity

\section{INTRODUCTION}

Rho-related GTPases from plants (ROPs), switch-like molecules between its GTP-binding active state and GDP-binding inactive state, play essential roles in controlling cell polarity development and cellular activities ( $\mathrm{Li}$ et al., 1998; Craddock et al., 2012), and are involved in cellular vesicular trafficking, cytoskeleton activities, cell-shape formation, root-hair development and pollen tube growth (Craddock et al., 2012). ROPs in Arabidopsis contain 11 ROPs family members from ROP1 to ROP11, wherein, AtROP2, AtROP4 and AtROP6 are all involved in polar cell growth and cell polarity, but AtROP6 functions antagonistically to AtROP2 and AtROP4 in the generation of jigsaw-shaped pavement cells (Craddock et al., 2012). In plant cells, the ROP6RIC1 signaling pathway participates in cortical microtubule ordering and cell expansion to keep jigsaw-puzzle appearance of pavement cells (Fu et al., 2009), and further study reveals that auxin acts upstream of AtROP6 and AtROP2 to control this process (Xu et al., 2010). The ROP6RIC1 signaling pathway is also involved in cortical microtubule arrangement via RIC1 physically interacting with microtubule severing protein katanin (KTN1) and activating its severing activity (Lin et al., 2013). In Arabidopsis roots and etiolated hypocotyls, auxin induces re-orientation of microtubule from transverse to longitudinal to inhibit cell expansion via ROP6-RIC1-KTN1 signaling pathway (Chen et al., 2014). The ROP6-RIC1 signaling pathway negatively regulates 
clathrin-mediated endocytosis and inhibits BFA-sensitive PINFORMED 1 (PIN1) and PIN2 auxin transporters' internalization to influence auxin-mediated root gravistimulation response and leaf vein pattern in Arabidopsis (Chen et al., 2012). SPIKE1, a DOCK family protein encoding a guanine nucleotide exchange factor in Arabidopsis, acts upstream of ROP6-RIC1 signaling pathway to maintain subcellular PIN2 polar distribution via inhibition of PIN internalization (Basu et al., 2008; Lin D. et al., 2012). SPIKE1 is also reported to activate AtROP2, AtROP4 and AtROP6 to modulate anisotropic growth and shape in Arabidopsis petal (Ren et al., 2016). ROP6 is also involved in cell development, pathogen response, F-actin bundle formation and symbiotic fungus growth in Arabidopsis (PoratyGavra et al., 2013; Venus and Oelmuller, 2013), and nodule formation in Lotus japonicas (Ke et al., 2012; Wang et al., 2015a,b).

Lipids, a class of amphoteric compounds in organisms comprising fatty acids, such as glycerolipids, glycerophospholipids, sphingolipids, sterol lipids, saccharolipids (Lam and Shui, 2013), play essential roles in cellular structures as well as cellular activities as signaling molecules. Phosphatidylinositol 4, 5-bisphosphate (PIP2), a phospholipid principally localized in the plasma membrane, functions as a necessary cofactor in the modulation of many ion channels and transporters in plasma membrane, including transient receptor potential (TRP) channel, voltage-gated $\mathrm{K}^{+}$channel superfamily, voltagegated $\mathrm{Ca}^{2+}$ channel, voltage-gated $\mathrm{Na}^{+}$channel, inwardrectifier $\mathrm{K}^{+}$channel, $\mathrm{Ca}^{2+}$ release channel, two- $\mathrm{P}$ domain $\mathrm{K}^{+}$ channel, and ion transporters such as the $\mathrm{Na}^{+} / \mathrm{H}^{+}$antiporter (Suh and Hille, 2008). KCNQ channel, a type of voltagegated $\mathrm{K}^{+}$channel, shows increased affinity to $\mathrm{PIP}_{2}$ when its arginine residues are methylated by methyltransferase, which further leads to seizure suppression in mice (Kim et al., 2016). Phosphatidic acid (PA) is considered as a second messenger in plants, which responses to many biotic and abiotic stresses such as wounding, plant defense and oxidative stress, osmotic stress, abscisic acid (ABA) treatment, ethylene treatment and Nod factor treatment (Munnik, 2001). In Arabidopsis, PA binds to MAP65-1 to regulate microtubule organization in response to salt stress (Zhang et al., 2012). In yeast, $\mathrm{PA}$ is considered as a $\mathrm{pH}$ biosensor that links membrane biogenesis to metabolism (Young et al., 2010). In mammalian cells, PA content is increased with mitogenic stimulation, and then interacts with the domain in mTOR (mammalian target of rapamycin) to activate mTOR downstream effectors (Fang et al., 2001). Phosphatidylserine (PS) was reported to play active roles in enteroviral infection, for PSenriched vesicles are more efficient in viral infection than single viral particles and PS is a co-factor for enteroviral infection in subsequent infectivity and transmission (Chen et al., 2015). Eicosapolyenoic acids in Arabidopsis are involved in ABA-mediated drought response; transgenic plants with higher eicosapolyenoic acids content are more sensitive to $\mathrm{ABA}$ and exogenous application of eicosapolyenoic acids can mimic ABA-mediated drought response (Yuan et al., 2014). Oleic acid (18:1) in Arabidopsis is involved in defense response by physically interacting with NOA1, leading to its degradation and regulating NO synthesis (Mandal et al., 2012). In Arabidopsis, sphingosine-1-phosphate (S1P) is reported to be a signaling molecule regulating ABA-mediated stomatal apertures and guard cell ion channel activities via heterotrimeric $G$ proteins downstream elements ( $\mathrm{Ng}$ et al., 2001; Coursol et al., 2003).

In Arabidopsis, AtROP6 is activated via association with lipid rafts by palmitic (C16:0) or stearic (C18:0) acids transient S-acylation in its cysteines (Sorek et al., 2010). As lipids in the plasma membrane are involved in regulating many membrane proteins' function (Munnik, 2001; Tejos et al., 2014), whether lipids are involved in AtROP6 regulation has never been reported. In this study, a phospholipid phosphatidylglycerol (PG) was identified to bind to AtROP6 in protein-lipid overlay assay, liposome sedimentation assay and microscale thermophoresis (MST) assay. PG was found both in roots and leaves with distinctive fatty acyl chain patterns. Exogenous application of PG activated AtROP6 activity, inhibited AtROP6-mediated endocytosis process, enhanced root gravitropic response, and regulated endocytosis process coordinately with 1-naphthylacetic acid (NAA). Thus, we suggest that PG physically binds to AtROP6, regulates its activity, and further influences AtROP6-mediated seedling polarity development.

\section{MATERIALS AND METHODS}

\section{Chemicals}

PC (phosphatidylcholine, catalog number 850375), PE (phosphatidylethanolamine, catalog number 850725), PG (phosphatidylglycerol, catalog number 841148), PA (phosphatidic acid, catalog number 840875), and DG (diglyceride, catalog number 800811) were purchased from Avanti Polar Lipids, Inc.; PI (phosphatidylinositol), PS (phosphatidylserine), DGDG (digalactosyldiacylglycerol), MGDG (monogalactosyldiacylglycerol), and SQDG (sulfoquinovosyl diacylglycerol) were purchased from Lipid Products, United Kingdom. LPA (lysophosphatidic acid, catalog number L7260), MG (monoglyceride, catalog number M7765), and NAA (1-naphthylacetic acid) were ordered from Sigma-Aldrich. FM4-64 was ordered from Molecular Probes, Inc.

\section{Plant Material and Growth Conditions}

All Arabidopsis thaliana lines used in this study are as follows: Columbia-0 (Col-0), 35S::GFP-ROP6 was kindly provided by Dr. Ying Fu (China Agricultural University), PIN2-GFP, rop6 $6^{\mathrm{CA}}$ and rop6-2 were kindly provided by Dr. Deshu Lin (Fujian Agriculture and Forestry University). Arabidopsis seeds were sterilized, sown on $0.443 \%$ (w/v) Murashige and Skoog salts (MS, Sigma-Aldrich) medium plus $20 \mathrm{~g} / \mathrm{L}$ sucrose ( $\mathrm{pH} 5.8$ ), and grown vertically or horizontally in controlled growth chamber at $22^{\circ} \mathrm{C}$ under 16-h light/8-h dark cycle for 5-10 days (light intensity of $50 \mu \mathrm{mol} \mathrm{m}{ }^{-2} \mathrm{~s}^{-1}$ ) unless indicated otherwise. For soil growth, the seedlings were then transferred to soil under a $16-\mathrm{h}$ light $\left(22^{\circ} \mathrm{C}\right) / 8$-h dark $\left(20^{\circ} \mathrm{C}\right)$ cycle. 


\section{Cloning, Expression, and Purification of AtROP6 Construct and Purification of MBP-RIC1 Construct}

The coding sequence of AtROP6 was amplified with the R6$\mathrm{Bf} / \mathrm{R} 6-\mathrm{Hr}$ primer and cloned into the pET-30a vector between the BamHI and Hind III sites to generate the recombinant plasmid pET-30a-AtROP6. The coding sequences of AtROP1 and AtROP3 were amplified with the R1-Ef/R1-Sr, R3-Ef/R3Sr primers and cloned into the pGEX-6p1 vector between the EcoRI and SalI sites to generate the recombinant plasmid 6p1AtROP1 and 6p1-AtROP3, respectively. The coding sequence of AtROP6 was amplified with the R6-Bf/R6-Er primer and cloned into the pGEX-6p1 vector between the BamHI and EcoRI sites to generate the recombinant plasmid 6p1-AtROP6. The coding sequence of $14-3-3 \lambda$ was amplified with the $\lambda$-Bf $/ \lambda$-Sr primer and cloned into the pGEX-6p1 vector between the BamHI and SalI sites to generate the recombinant plasmid 6p1-14-3-3 $\lambda$. Mutation of Thr-20 to Asn was generated by first amplification with the R6TN-f/R6-Er, R6-Bf/R6TN-r primers and second amplification with the R6-Bf/R6-Er primers, and then cloned into the pGEX$6 \mathrm{p} 1$ vector to generate the recombinant plasmid $6 \mathrm{p} 1-\mathrm{AtROP} 6^{\mathrm{DN}}$, or cloned into the pCAMBIA1390-GFP vector to generate the recombinant plasmid 1390-GFP-AtROP6 ${ }^{\mathrm{DN}}$. Mutation of Gly-15 to Val was generated by first amplification with the R6GV-f/R6Er, R6-Bf/R6GV-r primers and second amplification with the R6-Bf/R6-Er primers, and then cloned into the pGEX-6p1 vector to generate the recombinant plasmid $6 \mathrm{p} 1-\mathrm{AtROP} 6^{\mathrm{CA}}$, or cloned into the pCAMBIA1390-GFP vector to generate the recombinant plasmid 1390-GFP-AtROP6 ${ }^{\text {CA }}$. The plasmid was verified by sequencing and was then transformed into the bacterial strain BL21 or protoplast, respectively. Primer sequences are listed in Supplementary Table 1.

Bacterial cells were grown in Luria-Bertani medium supplemented with $50 \mathrm{mg} / \mathrm{L}$ kanamycin or $100 \mathrm{mg} / \mathrm{L}$ ampicillin at $37^{\circ} \mathrm{C}$ until cells reached an optical density $\mathrm{OD}_{600 \mathrm{~nm}}$ from 0.7 to 0.9 . The recombinant protein was expressed at $37^{\circ}$ overnight after induction with $0.4 \mathrm{mM}$ of IPTG. Proteins were purified using Ni-beads as described in the manufacturer's instructions.

The bacterial strain expressing MBP-RIC1 in pMAL21 construct was kindly provided by Dr. Ying $\mathrm{Fu}$ (China Agricultural University). MBP-RIC1-Conjugated Amylose Beads was prepared as described previously (Xu, 2012).

\section{Lipid-Protein Overlay Assay}

Stocks of phospholipids were first prepared in organic solvents according to the manufacturer's instructions or in the lipidsoluble solvent: DCM:MeOH: $\mathrm{H}_{2} \mathrm{O}$ 65:35:8 (v/v/v). Lipid-protein overlay assay was performed as described previously (Sun et al., 2013). Briefly, lipid test strip was prepared by spotting the indicated lipids with the amount of $5 \mathrm{nmol}$ onto a PVDF membrane and kept dry for $1 \mathrm{~h}$ at room temperature. The lipid test strip was incubated with $1 \mu \mathrm{g} / \mathrm{mL}$ of His fusion ROP6 protein in 3\% BSA-20 mM Tris- $\mathrm{HCl}(\mathrm{pH} \mathrm{8.0)}$ for $2 \mathrm{~h}$ at room temperature for blocking and incubation. After washing with PBST (0.1\% tween 20) buffer, the presence of bound ROP6 protein was detected using mouse anti-His-tag antibody as the primary antibody and goat anti-mouse antibody conjugated to HRP as the secondary antibody.

\section{Liposome Sedimentation Assay}

Stocks of phospholipids were first prepared in organic solvents according to the manufacturer's instructions or in the lipidsoluble solvent: DCM:MeOH: $\mathrm{H}_{2} \mathrm{O}$ 65:35:8 (v/v/v). Liposome sedimentation assay was performed as described previously (Sun et al., 2013). Briefly, liposome mixture was prepared with a weight ratio of 1:1 DOPC/DOPE and a serial weight ratio of PG. The total lipid weight was $200 \mu \mathrm{g}$. The solvent in the mixtures was first removed using nitrogen gas for $30 \mathrm{~min}$ without heating and kept dry in a desiccator overnight at room temperature. The lipids were then hydrated in $200 \mu \mathrm{L}$ buffer containing $100 \mathrm{mM} \mathrm{NaCl}$, $1 \mathrm{mM} \mathrm{NaN}_{3}$ and $20 \mathrm{mM}$ Tris- $\mathrm{HCl}\left(\mathrm{pH} \mathrm{6.8)}\right.$ ) at $67^{\circ} \mathrm{C}$ for $1 \mathrm{~h}$, during which time the lipids were mixed by pipetting up and down with a micropipette every $15 \mathrm{~min}$. After being freeze-thawed three times, the liposomes were formed by sonication. The liposomes were further pelleted, re-suspended in $40 \mu \mathrm{L}$ buffer containing $100 \mathrm{mM} \mathrm{NaCl}, 1 \mathrm{mM} \mathrm{NaN}_{3}$ and $20 \mathrm{mM}$ Tris-HCl (pH 6.8), and protein $(10 \mu \mathrm{g})$ was then added. Incubation was performed with the liposome for $30 \mathrm{~min}$ at room temperature. Centrifugation at 12,000 rpm gets liposome-bound pellet fraction and free-protein supernatant fraction, which were further analyzed by SDS-PAGE and Coomassie Blue Staining. Quantitation of protein content was performed with ImageJ software.

\section{Microscale Thermophoresis (MST) Assay}

MST assay was carried out using Monolith NT.115 instrument (NanoTemper Technologies) as described previously (Lin C.C. et al., 2012; Entzian and Schubert, 2016). The buffer with Tris salt in the purified recombinant proteins was first replaced with PBST buffer $(0.005 \%$ tween $20, \mathrm{pH}=7.5)$ using column A supplied by the manufacturer. Then the proteins at a final concentration of $5 \mu \mathrm{M}$ were labeled with excess NHS NT-647 dye at a molar ratio of 1:5 at room temperature for $30 \mathrm{~min}$ in the dark according to the manufacturer's instructions. Free unlabeled dye was removed using column B pre-equilibrated with PBST buffer (0.005\% tween $20, \mathrm{pH}=7.5)$. PG $(1 \mathrm{mg})$ was first dissolved in $50 \mu \mathrm{L}$ organic solvent DCM:MeOH: $\mathrm{H}_{2} \mathrm{O}$ 65:35:8 (v/v/v), and then dried with nitrogen gas for $30 \mathrm{~min}$ and kept dry in a desiccator overnight at room temperature. The dried PG was dissolved in $1 \mathrm{~mL}$ PBST buffer $(0.005 \%$ tween $20, \mathrm{pH}=7.5)$ by hydration for $1 \mathrm{~h}$ at room temperature until no lipid could be seen on the Eppendorf tube wall, and was then centrifuged at $12,000 \mathrm{rpm}$ for $10 \mathrm{~min}$ at room temperature to remove the possible existing pellet. The PG solution was serially diluted with PBST buffer and mixed with the same amount of labeled protein. The samples were loaded into capillaries (NanoTemper Technologies) and analyzed. The assay was carried out with 20\% LED power and 20\% MST power. Signal Thermophoresis + T-Jump Data were used for calculating dissociation constant $(\mathrm{Kd})$. Data was analyzed using software NT Analysis and Origin9.

\section{Chemical Treatment}

FM4-64 was dissolved in distilled water, BFA and cycloheximide (CHX) were dissolved in dimethyl sulfoxide, and NAA was 
dissolved in methanol. For phenotypic analysis, PG was dissolved in methanol. For other experiments, the solvent to dissolve PG was indicated in the experiment.

\section{ROP6 Activity Assay}

ROP6 activity assay was performed as described previously (Xu, 2012). ROP6 with activity could be pulled down by MBPRIC1-conjugated agarose beads, while ROP6 without activity could not be, so MBP-RIC1-conjugated agarose beads and GFPtagged ROP6 were both need to be prepared.

For preparation of MBP-RIC1-conjugated agarose beads, MBP-RIC in pMAL21 construct was transformed into Escherichia coli. Bacterial cells BL21 and the cells were cultured in LuriaBertani medium with $100 \mathrm{mg} / \mathrm{L}$ ampicillin at $37^{\circ} \mathrm{C}$. When the optical density of the cells reached about 0.8 , the cells were cooled to $16^{\circ} \mathrm{C}$ and $0.4 \mathrm{mM}$ of IPTG was added into the medium. The expression of MBP-RIC fusion protein was induced overnight at $16^{\circ} \mathrm{C}$ and then purified according to the manufacturer's instructions.

For preparation of GFP-tagged ROP6, 10-day-old 35S::GFPROP6 transgenic seedlings were treated with indicated amounts of PG or without PG in liquid 1/2 MS for $48 \mathrm{~h}$, and then the seedlings were grounded with liquid nitrogen and extracted at $4^{\circ} \mathrm{C}$ for $1 \mathrm{~h}$ in extraction buffer: $25 \mathrm{mM}$ Hepes, $10 \mathrm{mM} \mathrm{MgCl}_{2}$, $1 \mathrm{mM}$ EDTA, $100 \mathrm{mM} \mathrm{KCl,} 5 \mathrm{mM}$ DTT, $5 \mathrm{mM} \mathrm{Na} \mathrm{VO}_{4}, 5 \mathrm{mM}$ NaF, 1 mM PMSF, 1\% Triton X-100, pH 7.4, in which, DTT, $\mathrm{Na}_{3} \mathrm{VO}_{4}$, PMSF were added before use. After extraction, $50 \mu \mathrm{L}$ of the total protein was transferred out for the final total protein analysis, and for the reserved solution, the centrifugation of $10,000 \mathrm{~g}$ at $4^{\circ} \mathrm{C}$ was used to remove the debris and the same volume of extraction buffer without Triton X-100 was added into the total protein in the supernatant.

For preparation of GFP-tagged $\mathrm{ROP}^{\mathrm{CA}}$ and GFP-tagged $\mathrm{ROP}^{\mathrm{DN}}$, the plasmids were purified by $\mathrm{CsCl}$ gradient centrifugation. Then the Col-0 protoplasts were prepared and the plasmids were transformed into the protoplasts as described previously (Sheen, 2001). The GFP-tagged ROP6 ${ }^{C A}$ and GFP-tagged ROP $6^{D N}$ were prepared as described previously (Xu, 2012).

Then the MBP-RIC1-conjugated agarose beads were added into the supernatant and incubated at $4^{\circ} \mathrm{C}$ for $3 \mathrm{~h}$. After incubation, the beads were washed five times with washing buffer: $25 \mathrm{mM}$ Hepes, $5 \mathrm{mM} \mathrm{MgCl}$, $1 \mathrm{mM}$ EDTA, $1 \mathrm{mM}$ DTT. The MBP-RIC1 bound GFP-ROP6 was separated by SDS-PAGE and detected using mouse anti-GFP antibody as the primary antibody and goat anti-mouse antibody conjugated to HRP as the secondary antibody.

\section{FM4-64 Staining and PIN2 Internalization Observation}

FM4-64 staining was performed as described previously (Chen et al., 2012). Three-day-old seedlings were transferred to MS medium supplemented with or without indicated amounts of PG. After growing for $48 \mathrm{~h}$, the seedlings were first labeled with $2 \mu \mathrm{M}$ FM 4-64 for $5 \mathrm{~min}$, washed out for three times, and further incubated in liquid 1/2 MS medium for $20 \mathrm{~min}$ at room temperature. PIN2 internalization observation was performed as described previously (Chen et al., 2012). Three-day-old seedlings were transferred to MS medium supplemented with or without indicated amounts of PG. After growing for $48 \mathrm{~h}$, the seedlings were treated with $50 \mu \mathrm{M}$ BFA or $50 \mu \mathrm{M}$ BFA plus $5 \mu \mathrm{M}$ NAA for $2 \mathrm{~h}$. For confocal microscopy observation, the seedlings were mounted on glass slides in $10 \%$ glycerol for observation under confocal microscope (Andor Dradonfly spinning disk confocal, Nikon TiE microscope, plan APO $60 \times$, NA1.4 objective, and andor zyla4.2plus sCMOS camera) with excitation wavelength $561 \mathrm{~nm}$ and emission wavelength 620-650 nm for FM4-64 observation and excitation wavelength $488 \mathrm{~nm}$ and emission wavelength $507 \mathrm{~nm}$ for GFP observation. Quantitation of the fluorescence signal was performed with ImageJ software.

\section{Root Gravity Response Assay}

Five-day-old seedlings were transferred to the indicated amounts of PG-containing MS medium and applied recovered growth for $12 \mathrm{~h}$, and were then gravity stimulated for $12 \mathrm{~h}$ (at $90^{\circ}$ rotation). The root tips were labeled at indicated time periods and the angles formed were measured using ImageJ software.

\section{PG Content Analysis}

Quantitation of PG content in Arabidopsis was performed as described previously with minor modification (Milne et al., 2005; Hsu et al., 2007). Five-day-old seedlings were transferred to MS medium supplemented with or without $0.1 \mu \mathrm{M}$ NAA. After growing for 5 days, the root part and leaf part were collected separately using a scissor, and only $2 / 3$ root part near the root tip was collected to avoid hypocotyl contamination.

The samples were grounded under liquid nitrogen, and $200 \mu \mathrm{L}$ ice-cold 2:1 $\mathrm{CH}_{2} \mathrm{Cl}_{2}: \mathrm{CH}_{3} \mathrm{OH}$ (containing 0.25\% $12 \mathrm{M} \mathrm{HCl}, \mathrm{v} / \mathrm{v}$ ) was added into each sample. After a vortex for $2 \mathrm{~min}, 40 \mu \mathrm{L}$ of 1 $\mathrm{M} \mathrm{HCl}$ was added and vortexed for $30 \mathrm{~s}$. Then the samples were centrifuged for $5 \mathrm{~min}$ at $12,000 \mathrm{~g}$ at $4^{\circ} \mathrm{C}$, and the lower organic phase was transferred to a new tube and dried using a vacuum centrifuge (Eppendorf Concentrator plus). The extracted lipids were re-dissolved in $100 \mu \mathrm{L} \mathrm{CH}_{2} \mathrm{Cl}_{2}-\mathrm{CH}_{3} \mathrm{OH}-\mathrm{H}_{2} \mathrm{O}-300 \mathrm{mM}$ piperidine (1:1:0.2:0.1, v/v/v/v) for further HRESIMS (highresolution electrospray ionization-mass spectrometry) analysis (Thermo Fisher, Q-Exactive).

\section{RESULTS}

\section{PG Binds to AtROP6}

AtROP6, a plasma membrane-localized protein in Arabidopsis, functions as a molecular switch in many cellular signaling responses (Sorek et al., 2010; Craddock et al., 2012). To investigate whether lipids in the plasma membrane are involved in the regulation of AtROP6 function, we performed a proteinlipid overlay screen assay to look for the possible lipids that AtROP6 physically interacts with.

Glycerophospholipids including PA, PI, PS, PE, LPA, PG, PC and glycerolipids including MG, DG, MGDG, DGDG, SQDG are lipids that were reported to be located or possibly located at the plasma membrane (Manoharan et al., 1985; Ritter and Yopp, 
1993; Drøbak et al., 1994; Moreau et al., 1998; Andersson et al., 2003; Kim et al., 2004; Jouhet et al., 2007; Li et al., 2007, 2016; Yang et al., 2010; Dong et al., 2012). We spotted these lipids onto the PVDF membrane and performed the binding assay between these lipids and AtROP6. The recombinant protein His-ROP6 was purified from E. coli strain BL21 expressing recombinant plasmid pET-30a-AtROP6. The result showed that His-AtROP6 specially bound to PG, but not other lipids (Figure 1A). Further interaction assay between PG and His-casein kinase1like protein2 (CKL2) (Zhao et al., 2016), a negative control, revealed that PG specially bound to His-AtROP6, not His-CKL2 (Supplementary Figure 1A).

To further verify the interaction between PG and AtROP6, we performed a liposome sedimentation assay. We prepared control liposome containing only PC and PE, and also prepared PGcontaining liposomes. PG-containing liposomes were prepared with the same total lipid content as the control liposome by replacing equal amounts of PC and PE with PG. After incubation with the recombinant protein His-AtROP6, the liposomes were separated into the pellet and the supernatant by centrifugation, in which liposome-bound His-AtROP6 existed in the pellet and liposome-unbound His-AtROP6 existed in the supernatant. After analysis by SDS-PAGE and Coomassie Blue Staining, we found that the protein level of His-AtROP6 increased dramatically in the pellet with the elevated PG content in the liposomes (Figures 1B,C). This result supports the evidence that AtROP6 specially binds to PG, not PC and PE.

We also performed MST assay to investigate the binding affinity between AtROP6 and PG. To prepare the PG solution, we used PBST $(0.005 \%$ tween 20$)$ to hydrate PG to get the protein-compatible PG solution. His-AtROP6 was labeled with fluorescent dye and mixed with a series dilution of PG. The dissociation constant $(\mathrm{Kd})$ between His-AtROP6 and PG was determined to be $4.8 \pm 0.4 \mu \mathrm{M}$, while PG and fluorescent dye, His-AtROP6 and solvent (PBST, 0.005\% tween 20) had no interaction and could not be fitted (Figure 1D). These results suggest that AtROP6 specially binds to PG, and the dissociation constant is $4.8 \pm 0.4 \mu \mathrm{M}$.

To further investigate whether PG binds to other ROP protein family members, we performed liposome sedimentation assay and MST assay between PG and GST-AtROP1, GSTAtROP3 or GST-AtROP6. In the liposome sedimentation assay, after liposome preparation and protein incubation, we found that the protein level of GST-AtROP1, GST-AtROP3 and GSTAtROP6 increased in the pellet with the elevated PG content (Supplementary Figure 1B). By contrast, the negative control protein levels of GST-tag and GST-14-3-3 $\lambda$ in the pellet did not change with the increase of PG content in the liposomes (Supplementary Figure 1C). In the MST assay, the recombinant proteins were labeled with fluorescent dye and mixed with a series dilution of PG. The binding affinities between PG and GST-AtROP1, GST-AtROP3, or GST-AtROP6 were calculated as $22.4 \pm 0.7 \mu \mathrm{M}, 34.5 \pm 0.9 \mu \mathrm{M}$, or $11.6 \pm 0.3 \mu \mathrm{M}$ (Supplementary Figure 1D). The negative controls between GST tag and PG, and GST-14-3-3 $\lambda$ and PG had no interaction (Supplementary Figure 1D). These results indicate that other ROP protein family members AtROP1 and AtROP3 also bind to PG but with a little weaker interaction compared with AtROP6. The differences in the binding affinity between His-ROP6 and PG, and GST-ROP6 and PG might due to the influence of tag on ROP6 structure. We also performed the interaction test between PG and AtROP6 ${ }^{\mathrm{CA}}$ (mutation of Gly-15 to Val, a constitutively active form of ROP6) or AtROP $6^{\mathrm{DN}}$ (mutation of Thr-20 to Asn, a dominant negative form of ROP6), which showed that both GST-AtROP6 ${ }^{\mathrm{CA}}$ and GST-AtROP6 ${ }^{\mathrm{DN}}$ bound to PG in the liposome sedimentation assay (Supplementary Figure 2).

These results suggest that PG not only binds to AtROP6, but also binds to other ROP protein family members, such as AtROP1 and AtROP3.

\section{PG Activates AtROP6 Activity}

PG is widely studied as a thylakoid lipid in plants, which plays essential roles in oxygenic photosynthesis (Babiychuk et al., 2003; Kobayashi et al., 2016). PG is also reported to localize in the oat root with decreased content when plant is under phosphatelimitation condition (Andersson et al., 2003). However, the function of PG in the root has never been reported. In our study, we found that PG binds to AtROP6. To investigate what role PG binding to AtROP6 plays, we performed and AtRop6 activity assay. ROP6 activity could be analyzed by an effector bindingbased assay using RIC1, an effector of AtROP6, which specifically binds to the active form of ROP6 but not to the inactive form of ROP6 (Xu, 2012). To test the effect of PG on ROP6 activity, Arabidopsis seedlings expressing 35S::GFP-ROP6 were treated with indicated amounts of PG, followed by a pulled-down assay using MBP-RIC1-conjugated agarose beads and active ROP6 was detected with anti-GFP antibody. As shown in Figures 2A,B, we found that ROP6 activity was increased with the addition of PG and the activity displayed a dose-dependent manner with the increase of PG concentration. PC and PE were also applied on the seedlings expressing 35S::GFP-ROP6; however, no stimulation of ROP6 activity was seen (Supplementary Figure 3). In the interaction assay, PG also bound to AtROP6 ${ }^{\mathrm{CA}}$ and AtROP6 ${ }^{\mathrm{DN}}$, so we further performed a ROP6 activity assay both in the protoplasts expressing 35S::GFP-ROP6 ${ }^{\mathrm{CA}}$ and protoplasts expressing 35S::GFP-ROP6 ${ }^{\mathrm{DN}}$, and no stimulation effect was seen in either of them after PG treatment (Figure 2C). These results suggest that the interaction between PG and AtROP6 plays a role in stimulating AtROP6 activity.

\section{PG Exists Both in Arabidopsis Leaves and Roots but With Distinctive Fatty Acyl Chain Patterns}

Since PG activates AtROP6 activity, we want to investigate the distribution of PG species in Arabidopsis. The lipids from Arabidopsis leaves and roots were extracted separately, and then analyzed by mass spectrometry. By evaluating PG species, we found that PG existed both in leaves and roots but with distinctive fatty acyl chain patterns (Figures 3A-C). The PG from leaves showed nine species with the major species being C34:4-PG, which is similar to the work previously reported (Hsu et al., 2007). However, the PG from roots showed the major species being C34:3-PG. Besides C34:3-PG and C34:4-PG, all 

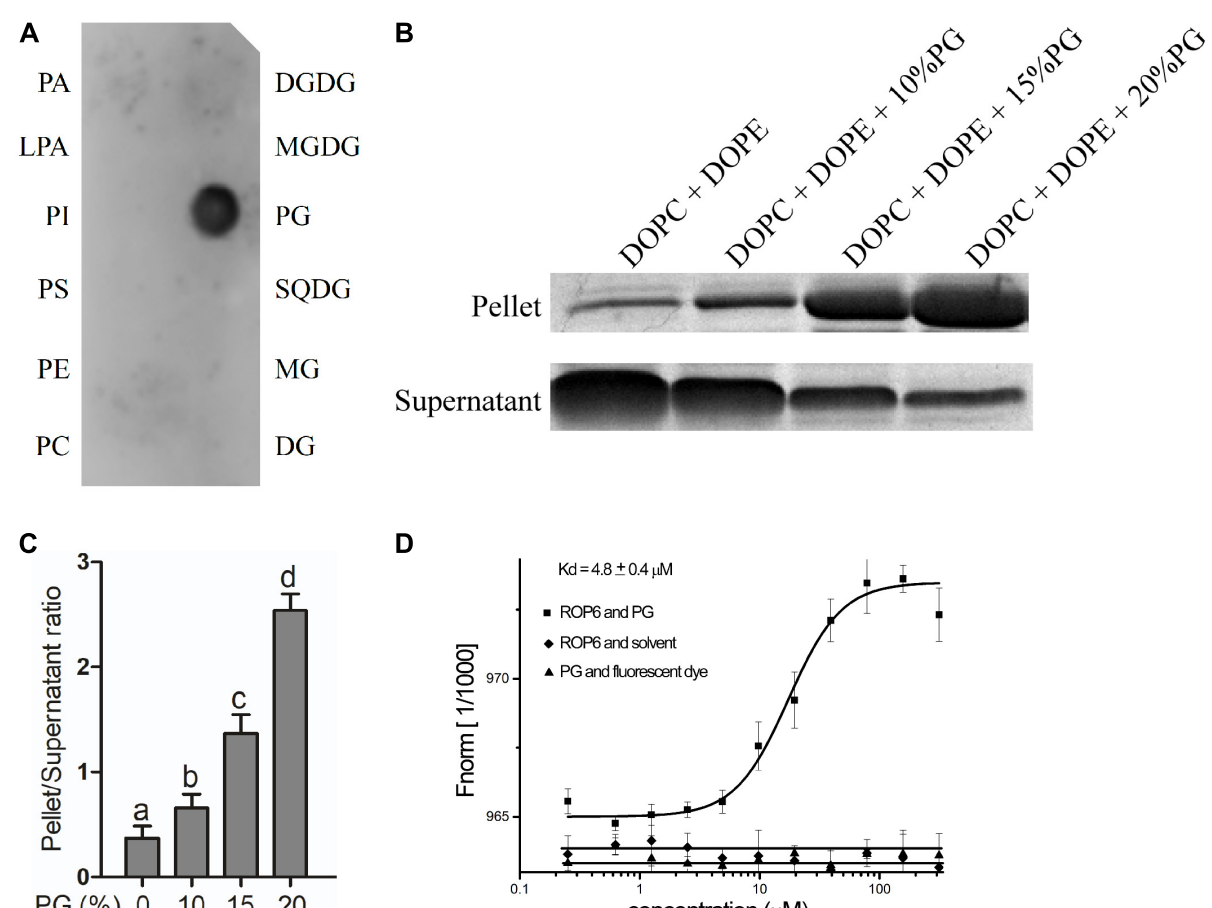

D

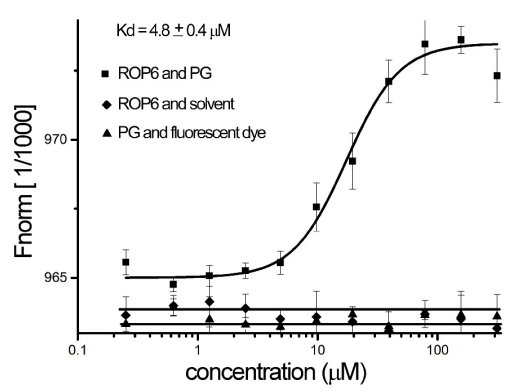

FIGURE 1 | PG binds to AtROP6. (A) Lipid-protein overlay screen assay between the recombinant protein His-AtROP6 and the lipids. His-AtROP6 was extracted and purified from E. coli. The amount of each lipid spot is $5 \mathrm{nmol}$. PA, Phosphatidic acid; LPA, Lysophosphatidic acid; PI, Phosphatidylinositol; PS, Phosphatidylserine; PE, phosphatidylethanolamine; PC, phosphatidylcholine; DGDG, digalactosyldiacylglycerol; MGDG, monogalactosyldiacylglycerol; PG, phosphatidylglycerol; SQDG, sulfoquinovosyl diacylglycerol; MG, monoglyceride, DG, diglyceride. (B) Liposome sedimentation assay between the recombinant protein His-AtROP6 and liposomes with or without PG. Liposome mixtures with a total lipid amount of $200 \mu \mathrm{g}$ were prepared by a weight ratio of 1:1 DOPC/DOPE and a serial weight ratio of PG. The amount of PG that each liposome contained is shown on the top. Liposomes were incubated with protein His-AtROP6 and centrifuged to get liposome-bound pellet protein fraction and supernatant protein fraction. Further detection use SDS-PAGE and Coomassie Blue Staining. (C) Ratio quantitation analysis of His-AtROP6 content in (B). The protein content in the supernatant and the pellet was performed quantitation separately using ImageJ software, and then the ratio was calculated. (D) Microscale thermophoresis assay between the recombinant protein His-AtROP6 and PG. His-AtROP6 was labeled with NHS NT-647 dye and kept at a constant concentration (100 nM). PG was hydrated in $1 \mathrm{~mL}$ PBST buffer $(0.005 \%$ tween 20 , pH $=7.5)$ to get the stock solution $1 \mathrm{mg} / \mathrm{mL}$. PG was titrated from $30 \mathrm{nM}$ to $300 \mu \mathrm{M}$ and the assay was carried out with 20\% LED power and 20\% MST power. The binding between His-AtROP6 and PG was fitted and the affinity was calculated as $4.8 \pm 0.4 \mu \mathrm{M}$. The negative controls are the bindings between His-AtROP6 and PBST buffer solvent, and between NHS NT-647 dye and PG, which all have no binding and could not be fitted. The bar represents the mean and the error bar represents the standard error. The data was calculated from at least three independent experiments. The statistical significance was analyzed by a Student's $t$-test and the significant differences $(P \leq 0.05)$ are indicated by lowercase letters.

other PG species showed dramatic difference between roots and leaves (Figures 3A-C). These results suggest that PG exists in Arabidopsis but with distinctive fatty acyl chain patterns between roots and leaves.

\section{PG Is Involved in AtROP6-Mediated Endocytosis Regulation}

AtROP6 was reported to function in membrane trafficking in plants (Chen et al., 2012). Amphiphilic styryl dye FM464 is a marker widely used to monitor endocytosis in plants, which stains plasma membrane and is integrated into vesicles accompanied by endocytosis process (Rigal et al., 2015). As AtROP6 regulates endocytosis in Arabidopsis in previous report (Chen et al., 2012), and PG bound to and activated AtROP6 in our study, we performed an endocytosis experiment to investigate whether PG is involved in this process. Arabidopsis seedlings of Col-0 were first applied treatment with indicated amounts of PG or solvent, and then the root was stained with
FM4-64 and endocytosis was observed. We found that, with PG treatment, the uptake of FM4-64 was reduced in wildtype Col-0 in a dose-dependent manner (Figures 4A,B), which is consistent with the PG concentration on ROP6 activity. When PG was applied at $20 \mu \mathrm{M}$, the endocytosis process in Col0 seedlings was almost completely inhibited, which is similar to that in rop6 $6^{\mathrm{CA}}$ (a constitutively active mutant of ROP6) (Figures 4A,B). When we also applied treatment with PC and PE on the seedlings of Col-0, no inhibition of FM4-64 uptake was seen (Supplementary Figures 4A,B). To further investigate whether $\mathrm{PG}$ inhibits endocytosis process through ROP6, we applied the same PG treatment on the rop6-2 mutant, which had been reported as a knockout mutant of ROP6 and showed increased endocytosis process in previous report (Chen et al., 2012). The endocytosis process in rop6-2 also displayed a dose-dependent inhibition with PG treatment and showed complete inhibition at $20 \mu \mathrm{M}$ (Figures 4A,B); however, the endocytosis process in rop6-2 showed an obvious slower rate 


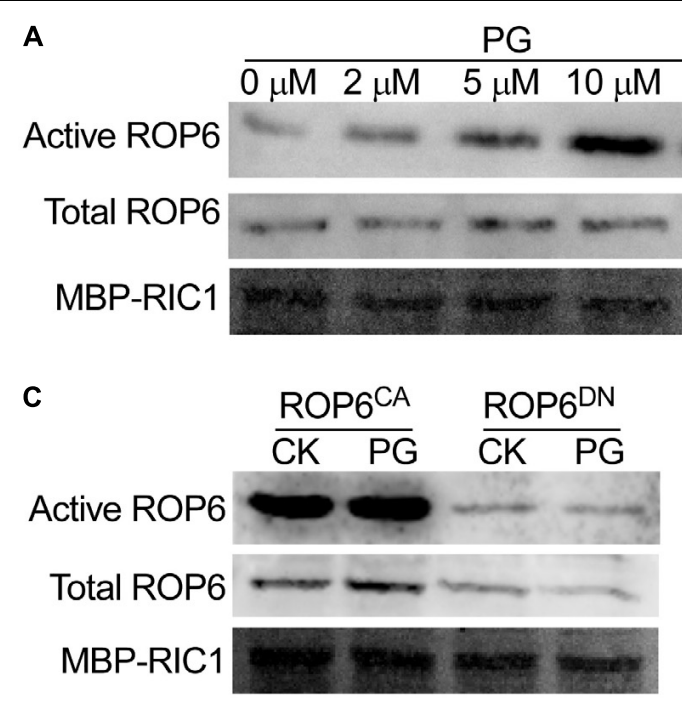

B

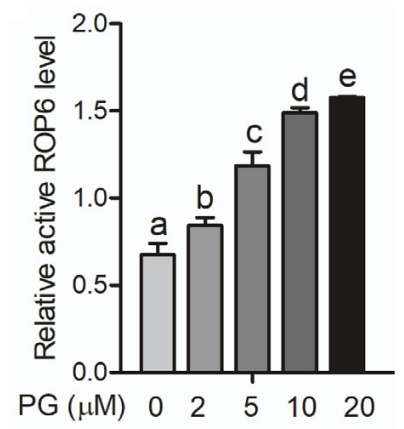

FIGURE 2 | PG activates AtROP6 in a dose-dependent manner. (A) Immunoblot analysis of active ROP6 and total ROP6 from 35S::GFP-ROP6 seedlings treated with indicated amounts of PG. The upper lane shows the immunoblot analysis of active ROP6, which was from MBP-RIC1 bound fraction. The middle lane shows the immunoblot analysis of total ROP6, which was prepared from total protein extraction. ROP6 was detected by immunoblot using anti-GFP antibody. The lower lane shows the Coomassie Brilliant Blue staining of MBP-RIC1 on PVDF membrane after immunoblot analysis. (B) Relative active ROP6 level in (A). The amount of active ROP6 and total ROP6 was performed quantitation separately using Image J software, and then the amount of active ROP6 was divided by the amount of total ROP6 to get the relative active ROP6 level. (C) Immunoblot analysis of active ROP6 and total ROP6 from 35S::GFP-ROP6 CA and 35S::GFP-ROP6DN seedlings treated with $20 \mu \mathrm{M}$ PG. The upper lane shows the immunoblot analysis of active ROP6. The middle lane shows the immunoblot analysis of total ROP6. ROP6 was detected by immunoblot using anti-GFP antibody. The lower lane shows the Coomassie Brilliant Blue staining of MBP-RIC1 on PVDF membrane after immunoblot analysis. The bar represents the mean and the error bar represents the standard error. The data was calculated from at least three independent experiments. The statistical significance was analyzed by a Student's $t$-test and the significant differences $(P \leq 0.05)$ are indicated by lowercase letters.

in the reduction of FM4-64 uptake compared with Col-0 at lower PG concentrations of 2 and $5 \mu \mathrm{M}$ (Figure 4C). These results indicate that the endocytosis process in plants could be inhibited by $\mathrm{PG}$, and the inhibition is partially through ROP6.

\section{PG Regulates Endocytosis Process Coordinately With Auxin}

Auxin inhibits endocytosis process in plants, thereby internalization of PIN-FORMED (PIN) proteins of auxin transporters is inhibited and further auxin efflux is promoted (Paciorek et al., 2005; Chen et al., 2012). As ROP6 is required for auxin inhibition of endocytosis in the previous report (Chen et al., 2012), and PG is involved in AtROP6-mediated endocytosis regulation in our study, we applied NAA treatment to investigate whether $P G$ is involved in the auxin inhibition of endocytosis process. Brefeldin A (BFA) is a fungal toxin repressing the endosomal recycling of plasma membrane proteins in plants, which could induce PIN protein aggregation and form BFA bodies in the cytoplasm (Irani and Russinova, 2009; Chen et al., 2012). We first applied BFA treatment on the seedlings of Arabidopsis Col-0 in PIN2-GFP background to investigate the internalization of PIN2 signals, which showed BFA-induced PIN2 aggregates in the cytoplasm of epidermal cells (Figures 5A,B). To exclude the possibility that the accumulation of BFA bodies came from de novo PIN2-GFP synthesis, we applied a protein synthesis inhibitor $\mathrm{CHX}$ to investigate this process. CHX blocks translational elongation step in protein synthesis and is widely used as a protein synthesis inhibitor (Paciorek et al., 2005; Pan et al., 2009; Wang et al., 2016). Consistent with previous report (Pan et al., 2009), PIN2-GFP accumulation in BFA bodies was still observed in the presence of CHX (Supplementary Figures 5A,B). When PG was applied on the treatment, the accumulation of BFA bodies was decreased (Figures 5A,B), which is consistent with the PG inhibition on the uptake of FM4-64. When we applied treatment with PC and PE on the seedlings, no inhibition of BFA bodies was seen (Supplementary Figures 6A,B). Then we performed this BFA-induced PIN2 internalization experiment with NAA treatment, which showed that auxin inhibits PIN2 internalization as previously reported (Paciorek et al., 2005; Pan et al., 2009; Chen et al., 2012) however, PIN2-GFP accumulation in the BFA bodies upon NAA treatment (Figures 5C,D) was much less than that in the mock treatment (Figures 5A,B) in the seedlings pre-treated with PG, indicating that PG enhances NAA effect on the inhibition of endocytosis. To investigate whether PG affects exocytosis, we performed a BFA washout experiment to restore PIN2-GFP signals at the plasma membrane, which showed that the BFA bodies have no significant difference in all the seedlings with or without PG treatment (Supplementary Figures 7A,B). This indicates that PG inhibits endocytosis process, but not exocytosis process.

To investigate whether the content of PG changes with NAA treatment, we performed PG content analysis from Arabidopsis roots with or without NAA treatment using mass spectrometry. With $0.1 \mu \mathrm{M}$ of NAA treatment, C34:3-PG, the major species of 

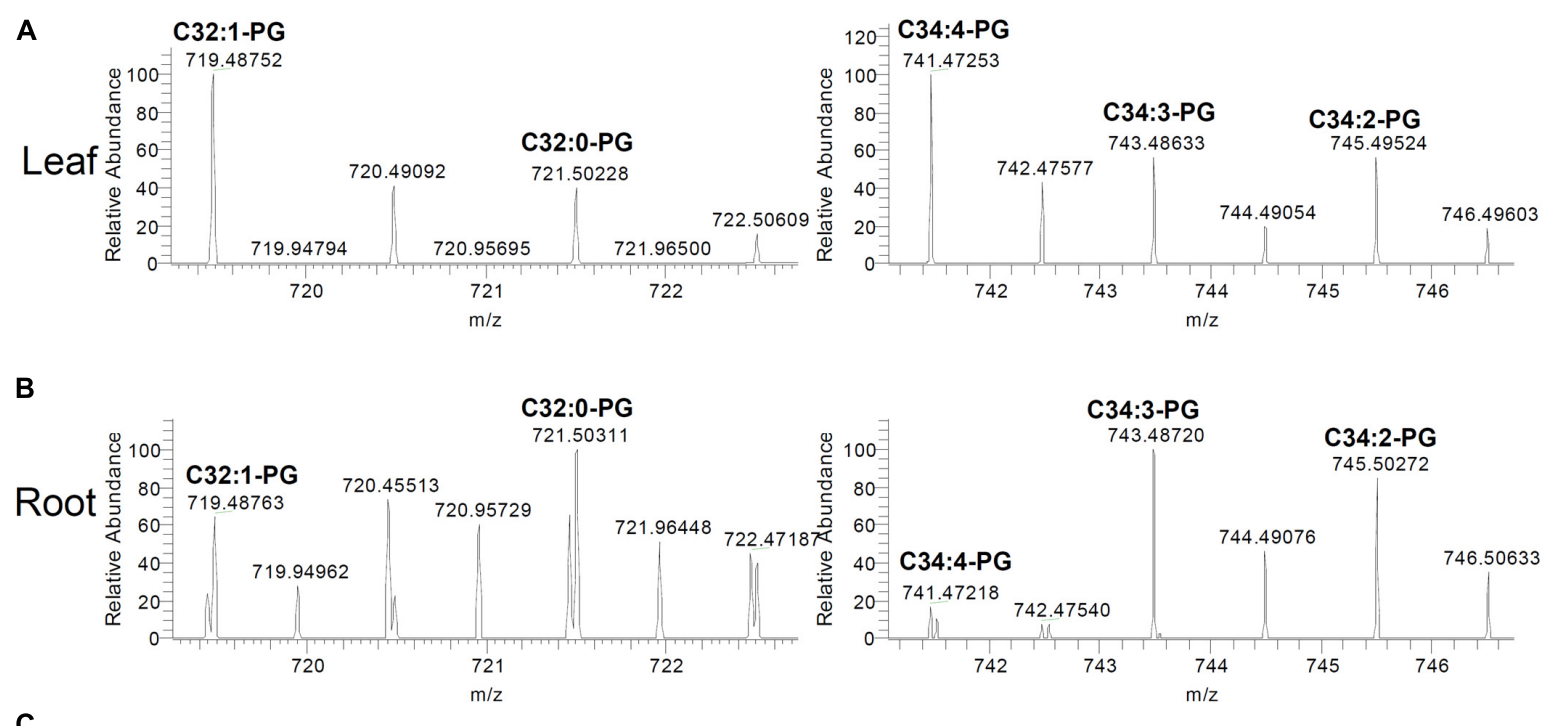

c

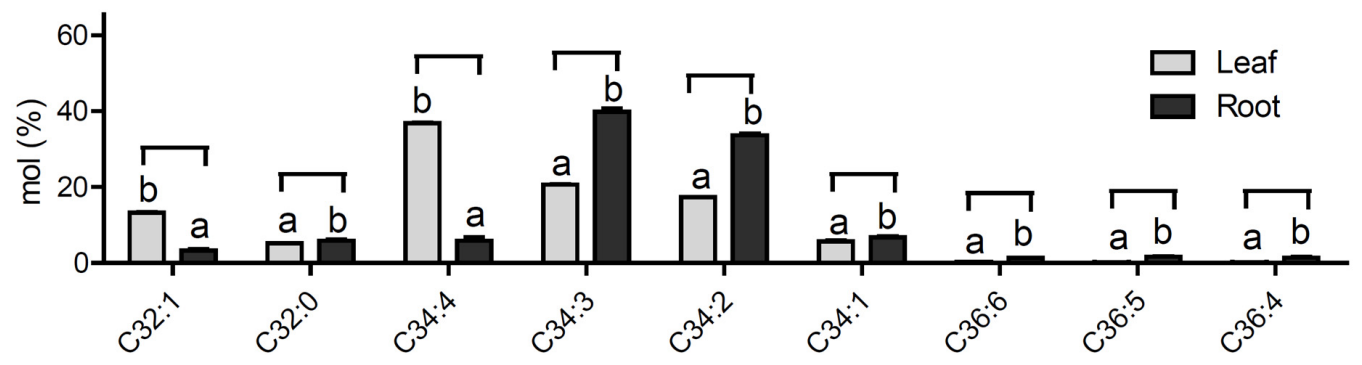

FIGURE 3 | PG exists both in leaves and roots with distinctive fatty acyl patterns. (A) The high-resolution mass spectrum of PGs from Arabidopsis leaves ([M-H]$\mathrm{ESI}^{-}$). 719.48752 C32:1-PG (calcd. for $\mathrm{C}_{38} \mathrm{H}_{72} \mathrm{O}_{10} \mathrm{P}: 719.48631$ ); m/z 721.50228 C32:0-PG (calcd. for $\mathrm{C}_{38} \mathrm{H}_{74} \mathrm{O}_{10} \mathrm{P}: 721.50196$ ); m/z 741.47253 C34:4-PG (calcd. for $\left.\mathrm{C}_{40} \mathrm{H}_{70} \mathrm{O}_{10} \mathrm{P}: 741.47066\right)$ ); m/z 743.48633 C34:3-PG (calcd. for $\mathrm{C}_{40} \mathrm{H}_{72} \mathrm{O}_{10} \mathrm{P}: 743.48631$ ); m/z 745.49524 C34:2-PG (calcd. for $\mathrm{C}_{40} \mathrm{H}_{74} \mathrm{O}_{10} \mathrm{P}$ :

745.50196). (B) The high-resolution mass spectrum of $P G s$ from Arabidopsis roots ([M-H $]^{-}, E S I^{-}$). $719.48763 \mathrm{C}_{2}: 1-P G\left(c a l c d\right.$. for $\mathrm{C}_{38} \mathrm{H}_{72} \mathrm{O}_{10} \mathrm{P}: \mathrm{P}_{19.48631)} \mathrm{m} / \mathrm{z}$

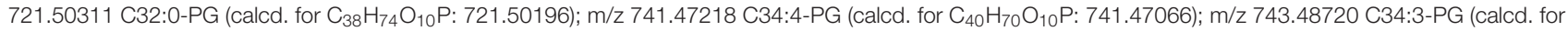
$\mathrm{C}_{40} \mathrm{H}_{72} \mathrm{O}_{10} \mathrm{P}: 743.48631$ ); m/z 745.50272 C34:2-PG (calcd. for $\mathrm{C}_{40} \mathrm{H}_{74} \mathrm{O}_{10} \mathrm{P}:$ : 745.50196). (C) PG composition analysis in the lipid extracts of Arabidopsis leaves and roots. The bar represents the mean and the error bar represents the standard error. The data were calculated from three independent experiments. The statistical significance was analyzed by a Student's t-test and the significant differences $(P \leq 0.05)$ are indicated by lowercase letters.

PG in the root, increased with NAA treatment, and the other PG species showed no significant difference compared with seedlings without NAA treatment (Figure 5E).

\section{PG/ROP6 Signaling Pathway Is Involved in AtROP6-Mediated Root Gravity Response}

It was reported that ROP6 pathway acts downstream of auxin in the regulation of endocytosis process in Arabidopsis roots (Chen et al., 2012). Root gravity response in plants is an auxinmediated developmental process beneficial for plant adaption to its environment and ROP6 is required for this seedling development (Chen et al., 2012). Previous reports showed that the roots in $r o p 6^{\mathrm{CA}}$ exhibit a hypergravitropic response, whereas display an attenuated gravitropic response in lossof-function mutant rop6-2 (Chen et al., 2012; Lin D. et al., 2012). To determine whether $P G$ regulates root gravity response in Arabidopsis, seedlings of Col-0 were applied treatment with indicated amounts of PG or solvent, and reoriented by $90^{\circ}$ for gravity stimulation. We found that root gravitropic bending curvatures increased with the treatment of $P G$ in a dose-dependent manner at all time points after gravity stimulation (Figures 6A-C), which is consistent with the PG concentration on the ROP6 activity and endocytosis phenotype except that the treatment of PG at $20 \mu \mathrm{M}$ did not show regular pattern on root gravity response and $50 \mu \mathrm{M}$ showed a waved pattern on root growth (Supplementary Figure 8). As negative control, PC and PE did not change root gravitropic bending curvatures in Col-0 seedlings (Supplementary Figures 9A,B). As root gravity response is dependent on root growth, we applied PG treatment to investigate whether PG influences root growth. After measuring the root length of the seedlings, we found that PG did not enhance root growth (Supplementary Figures 10A,B). We further investigated the PG effect on the rop6-2 mutant seedlings, which also exhibited an increase in gravitropic bending curvatures after seedling re-orientation, but was much less compared with Col-0 seedlings at PG concentrations of 2 and $5 \mu \mathrm{M}$ (Figures $\mathbf{6 A}, \mathbf{B}, \mathbf{D}$ ), suggesting that PG elevates gravity response partially through ROP6. Taken 


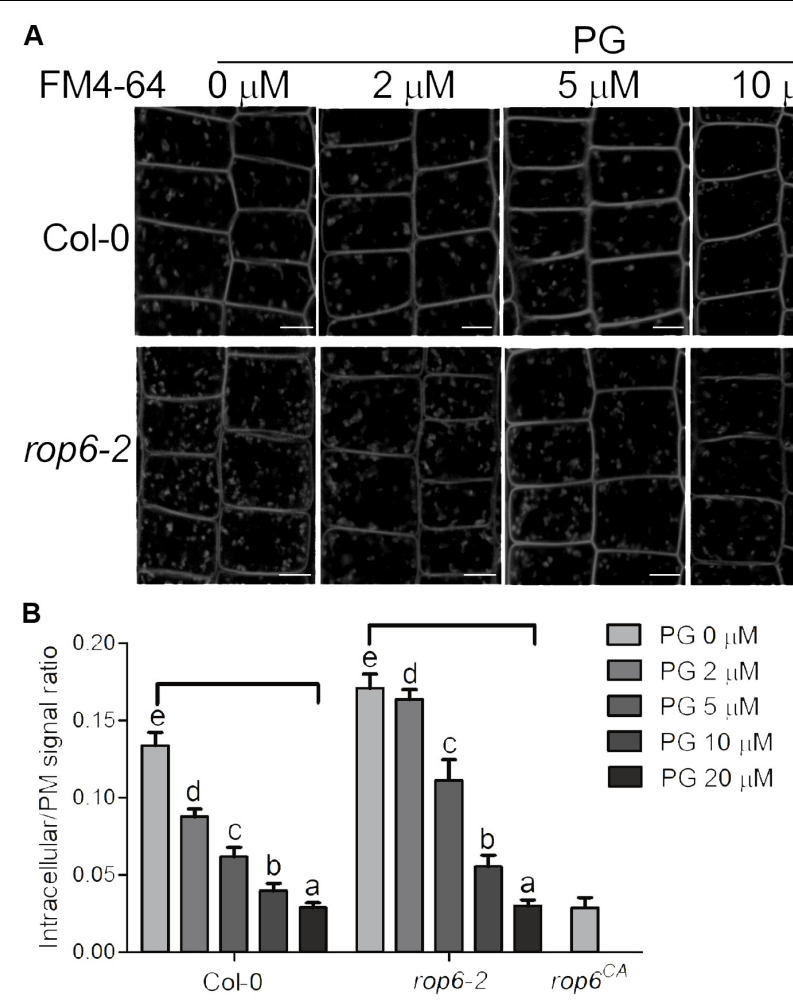

FIGURE 4 | PG positively regulates ROP6-mediated endocytosis regulation. (A) FM4-64 uptake in the seedlings of Col-0, rop6-2 and rop6 ${ }^{\mathrm{CA}}$. Seedlings of Col-0 and rop6-2 were treated with indicated amounts of PG, and then stained with FM4-64 to observe endocytosis process. The amount of PG that each treatment used was shown on the top. The upper lane shows the FM4-64 uptake in the seedlings of Col-0. The lower lane shows the FM4-64 uptake in the seedlings of rop6-2. rop6 ${ }^{\mathrm{CA}}$ was stained with FM4-64 and observed for endocytosis process. Scale bar represents $5 \mu \mathrm{m}$. (B) Ratio quantitation analysis of FM4-64 signal in (A) in bar graph. The FM4-64 signal in the cytoplasm and the plasma membrane was performed measurement separately using ImageJ software, and then the ratio was calculated $(n>20)$. (C) Ratio quantitation analysis of FM4-64 signal between Col-0 and rop6-2 in (B). The bar represents the mean and the error bar represents the standard error. The data were calculated from at least three independent experiments. The statistical significance was analyzed by a Student's t-test and the significant differences $(P \leq 0.05)$ are indicated by lowercase letters.

together, these results indicate that PG regulates the root gravity response in Arabidopsis and this regulation is partially through ROP6.

\section{DISCUSSION}

Lipids play essential roles in cellular activities and mainly function as building blocks for the membrane structure, signaling molecules in the signal transduction, and membrane lipid environment for the function of membrane proteins (Bogdanov et al., 2009; Bogdanov et al., 2014; Dowhan, 2017). Many qualitative assays of the protein-lipid interaction have been developed and reported. Nuclear magnetic resonance (NMR) is an accurate and widely used technique; however, NMR is limited to the high requirement for proteins in the molecular weight, purity and stability. Liposome sedimentation assay is an acknowledged method to study lipid-protein interactions, with liposome being prepared and target proteins being precipitated on the liposome (Baron and Malhotra, 2002; Sun et al., 2013). Isothermal titration calorimetry (ITC) (Swamy and Sankhala, 2013), surface plasmon resonance (SPR) (Del and Stahelin,
2016), and MST (Dijkman and Watts, 2015) are quantitative techniques widely applied to study lipid-protein interactions and could afford binding constant. The protein-lipid overlay (PLO) assay is also a widely used technique to study lipid-protein interactions (Baron and Malhotra, 2002; Dowler et al., 2002; Munnik and Wierzchowiecka, 2013; Sun et al., 2013). Here, we applied a PLO screen assay to investigate the lipids that might interact with AtROP6, a plasma membrane switch-like molecule in Arabidopsis, functioning in cell polarity development and cellular activities. We found that AtROP6 specially binds to PG, not other lipids in our PLO screen assay. Further liposome sedimentation assay and MST assay verified the binding between PG and AtROP6. In our AtROP6 activity assay, we found that PG could activate AtROP6, inhibit FM4-64 uptake in the membrane trafficking, and regulate root gravity response through ROP6. Taken together, our attempt to study lipid-protein interaction let us find a phospholipid, PG, binds and regulates ROP6 activity in cellular activities.

Endocytic pathways in plants have been identified as clathrinmediated endocytosis and membrane microdomain-associated endocytosis (Fan et al., 2015). Previous studies show that ROP6 regulates clathrin-mediated endocytosis (Chen et al., 2012; 


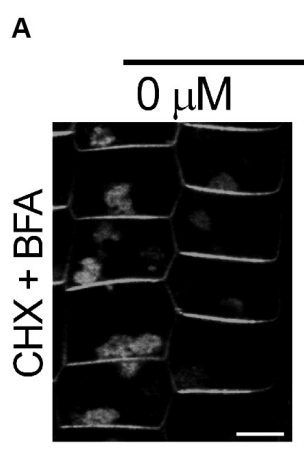

C

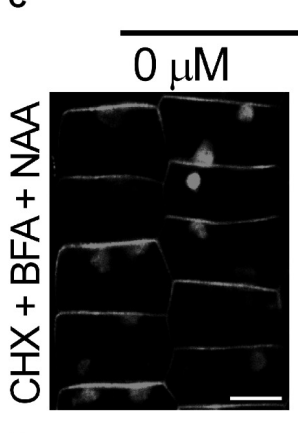

\section{PG}

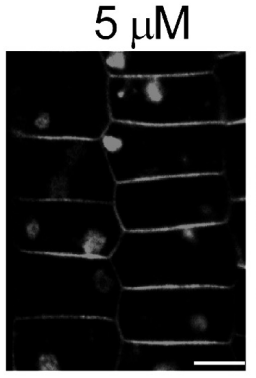

PG

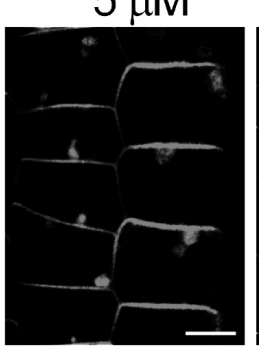

\section{$20 \mu \mathrm{M}$}
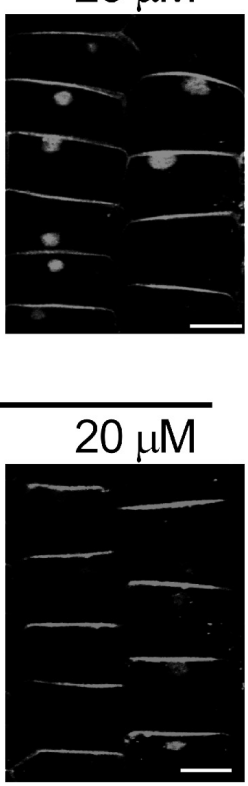

B

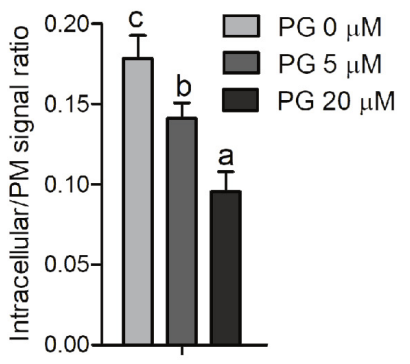

D

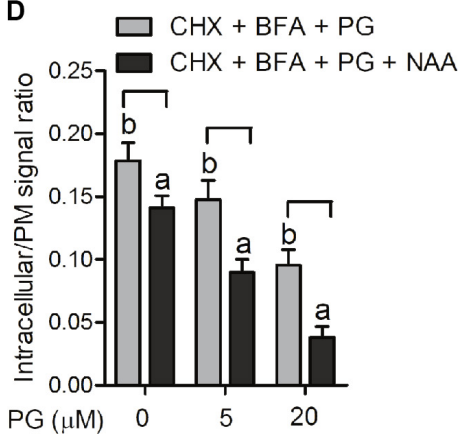

E

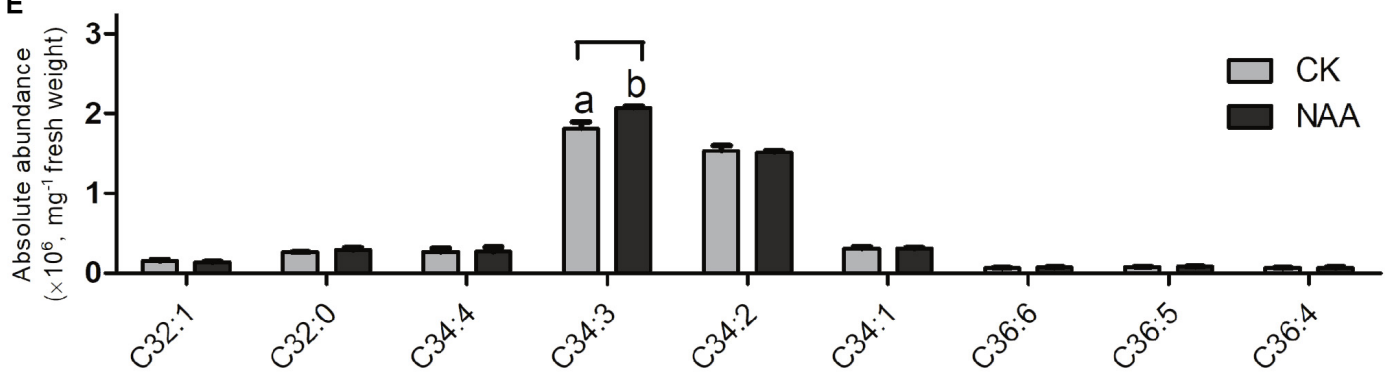

FIGURE 5 | PG regulates endocytosis process coordinately with auxin. (A) The seedlings (PIN2-GFP in Col-0 background) were treated with indicated amounts of PG for 2 days, followed by treatment with $\mathrm{CHX}$ and indicated amounts of PG for $60 \mathrm{~min}$, and then by treatment with CHX, BFA and indicated amounts of PG for $2 \mathrm{~h}$. The concentration of the chemicals used: $\mathrm{CHX}, 50 \mu \mathrm{M}$; BFA, $50 \mu \mathrm{M}$. The amount of PG that each treatment used was shown on the top. Scale bar represents $5 \mu \mathrm{m}$. (B) Ratio quantitation analysis of PIN2-GFP signal in (A). The PIN2-GFP signal in the cytoplasm and the plasma membrane was measured separately using ImageJ software, and then the ratio was calculated $(n>20)$. (C) BFA-induced PIN2 internalization was more inhibited by PG and NAA. The seedlings (PIN2-GFP in Col-0 background) were treated with indicated amounts of PG for 2 days, followed by treatment with $\mathrm{CHX}$ and indicated amounts of PG for 30 min, and by treatment with $\mathrm{CHX}, \mathrm{NAA}$ and indicated amounts of PG for another $30 \mathrm{~min}$, and then by treatment with CHX, NAA, BFA and indicated amounts of PG for $2 \mathrm{~h}$. The concentration of the chemicals used: $\mathrm{CHX}, 50 \mu \mathrm{M}$; BFA, $50 \mu \mathrm{M}$, NAA $5 \mu \mathrm{M}$. The amount of PG that each treatment used was shown on the top. Scale bar represents $5 \mu \mathrm{m}$. (D) Ratio quantitation analysis of PIN2-GFP signal in (A). PG content analysis in the lipid extracts of Arabidopsis roots with or without NAA treatment (E). The PIN2-GFP signal in the cytoplasm and the plasma membrane was performed measurement separately using ImageJ software, and then the ratio was calculated $(n>20)$. The bar represents the mean and the error bar represents the standard error. The data were calculated from at least three independent experiments. The statistical significance was analyzed by a Student's $t$-test and the significant differences $(P \leq 0.05)$ are indicated by lowercase letters.

Nagawa et al., 2012; Wang et al., 2015a,b), and some other ROP protein family members are reported to be involved in membrane trafficking (Bloch et al., 2005; Lee et al., 2008; Nagawa et al., 2012). Since PG also bound to AtROP1 and AtROP3 in our study (Supplementary Figures 1B,D) and many components exist in the endocytosis process (Paciorek et al., 2005; Chen X. et al., 2011; Wang et al., 2013, 2016; Fan et al., 2015), it is possible that either other ROP protein family members or other components in the endocytic pathway are involved in this process to inhibit endocytosis process coordinately with AtROP6, which need further experiment to investigate it.
In the root gravitropism experiment, PG elevated gravity response both in Col-0 seedlings and rop6-2 seedlings, but the rop6-2 seedlings showed less sensitivity to PG compared with Col-0 seedlings, which further indicate that PG regulates cellular activities partially through AtROP6, and AtROP6 is not the only target protein of PG. In view of the former studies, many lipids have more than one protein target, such as phosphoinositides in Arabidopsis, which have many protein targets including PHdomain containing proteins, FYVE-domain containing proteins and PX-domain containing proteins (Lemmon, 2003; Leeuwen et al., 2004; Simon et al., 2014; Heilmann, 2016a,b). Phosphatidic 
A A
B

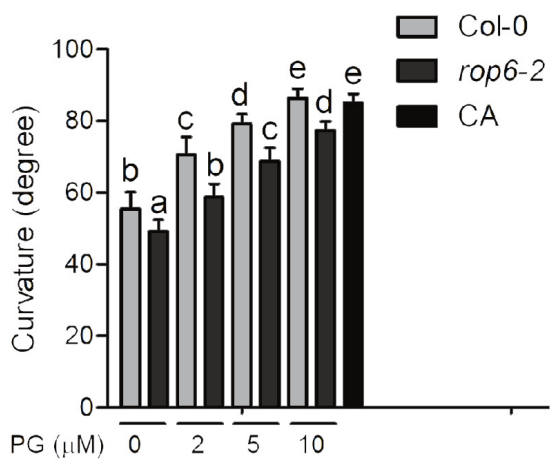

C

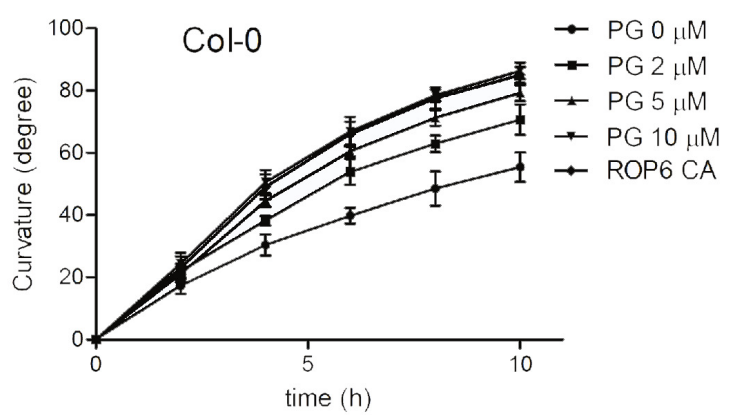

D

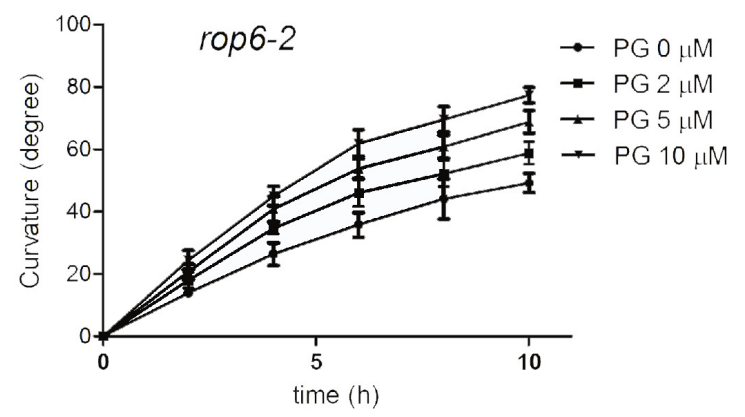

FIGURE 6 | PG positively regulates ROP6-mediated gravitropic response. (A) Gravitropic response in the seedlings of Col-0, rop6-2 and rop6 CA . Seedlings of Col-0 and rop6-2 were treated with indicated amounts of PG for $10 \mathrm{~h}$, and then rotated $90^{\circ}$ for gravistimulation. The amount of PG that each treatment used was shown on the top. The upper lane shows the gravitropic response in the seedlings of Col-0. The lower lane shows the gravitropic response in the seedlings of rop6-2. rop6 ${ }^{\mathrm{CA}}$ was rotated $90^{\circ}$ for gravistimulation. (B) Root tropic bending curvatures of Col- 0 and rop6-2 at $10 \mathrm{~h}$ after re-orientation. (C) Root tropic bending curvatures of Col-0 after re-orientation at intervals of $2 \mathrm{~h}$. (D) Root tropic bending curvatures of rop6-2 after re-orientation at intervals of $2 \mathrm{~h}$. The bar represents the mean and the error bar represents the standard error. The data were calculated from at least three independent experiments. The statistical significance was analyzed by a Student's $t$-test and the significant differences $(P \leq 0.05)$ are indicated by lowercase letters.

acid in Arabidopsis was also reported to have many protein targets, such as ABI1 phosphatase 2C (Zhang et al., 2004), MAP65-1 (Zhang et al., 2012), and MPK6 (Yu et al., 2010). Because the target proteins of PG were studied less in Arabidopsis, further study would be possible to look for the other target proteins of PG.

In plants, PG was most widely studied as building block of thylakoid membrane, which plays crucial roles for oligomerization of photosystem I reaction center, electron transfer both in donor and acceptor sides of photosystem II, and the loss of PG biosynthesis in Arabidopsis has impaired oxygenic photosynthesis during seedling growth (Domonkos et al., 2004; Kobayashi et al., 2016). Besides functioning in oxygenic photosynthesis, PG was also reported to be involved in the phospholipids-galactolipids transition when plant was under phosphate-deprivation condition (Andersson et al., 2003; Frentzen, 2004). Detection of PG content revealed that PG exists in Arabidopsis leaves with kinds of fatty acyl chains, and also exists in oat roots with non-specific fatty acyl chains (Andersson et al., 2003; Frentzen, 2004; Hsu et al., 2007). The PG-target proteins have not been reported in plants. In our study, we found that PG interacted with AtROP6 and stimulated its activity. Further PG content analysis in Arabidopsis revealed that PG existed both in roots and leaves but with different fatty acyl chain patterns, which indicates that PG may have distinct function in the roots from leaves. Taken together, AtROP6 might be one of PG-target proteins in the regulation of cellular activities.

Since AtROP6 acts downstream of auxin to control cell polarity development and cellular activities, we analyzed root PG content with or without NAA treatment using mass spectrometry. The result showed that only C34:3-PG, the major constituent of PG in the root, increased with NAA treatment, while other PG species did not change. However, the link between C34:3-PG and the regulation of AtROP6 activity was unclear in our study, which needs a further experiment to isolate different fatty acyl chain patterns of PG from plant or synthesis them to investigate the fatty acyl chain patterns of PG on the regulation of AtROP6 in the endocytosis process. Since lipids 
in the cell membrane are distributed asymmetrically (Maekawa and Fairn, 2014), it is also possible that the distribution of PG in the membrane might be involved in the regulation of AtROP6 activity. Interestingly, in bacteria, PG could regulate the activity of E. coli GTPase FtsY by binding to its C-terminal GTP-binding domain with the same concentration of $\mathrm{PG}$ as we applied on AtROP6. By using Fourier transform infrared (FT-IR) spectroscopy, PG was found to enhance FtsY GTPase activity through changing its conformation (de Leeuw et al., 2000). Whether PG in the plasma membrane interacts with the regulation part of ROP6 to change its conformation or the different conformations exist between ROP6, ROP6 ${ }^{\mathrm{CA}}$ and $\mathrm{ROP}^{\mathrm{DN}}$, which would lead to the variability of ROP6 activity, remains unclear in our study and need further experiments to investigate it.

The ROP GTPase family members serve as critical signal transducers participating in many fundamental cellular activities including cell polarity, cell development, as well as abiotic and biotic stress signaling events (Craddock et al., 2012; Zhang et al., 2014; Lin et al., 2015). In Arabidopsis, AtROP1, AtROP3, and AtROP5 may be involved in the regulation of tip growth of pollen tubes redundantly ( $\mathrm{Gu}$ et al., 2003; Craddock et al., 2012), wherein, AtROP1 transcript level in pollen is much more abundant than that of AtROP3 and AtROP5, and may play a dominant role in this process and has been extensively studied (Kost et al., 1999; Li et al., 1999, 2008; Gu et al., 2003, 2005, 2006; Hwang et al., 2005, 2010; Zhang and McCormick, 2007; Lee et al., 2008; Wang et al., 2008; Chang et al., 2013; Takeuchi and Higashiyama, 2016; Luo et al., 2017). AtROP3 contributes to polar auxin transport and distribution to control plant patterning and auxin-regulated responses (Huang et al., 2014), and is also activated by RopGEF7 and involved in the regulation of PLETHORA-dependent maintenance of the root stem cell niches (Chen M. et al., 2011). Studies on ROP GTPases in plants also uncover their roles in division plane selection mitotic events (Stockle et al., 2016), biotic stress responses (Venus and Oelmuller, 2013; Zhang et al., 2014), and ABA responses (Craddock et al., 2012). As a molecular switch in cellular activities, ROP GTPases in plants are regulated by many signal molecules such as auxin, ABA, calcium (Li et al., 1999; Yu et al., 2012; Peer, 2013; Miyawaki and Yang, 2014), and by receptor-like kinases such as FERONIA, PRK6

\section{REFERENCES}

Andersson, M. X., Stridh, M. H., Larsson, K. E., Liljenberg, C., and Sandelius, A. S. (2003). Phosphate-deficient oat replaces a major portion of the plasma membrane phospholipids with the galactolipid digalactosyldiacylglycerol. FEBS Lett. 537, 128-132. doi: 10.1016/S0014-5793(03)00109-1

Babiychuk, E., Müller, F., Eubel, H., Braun, H.-P., Frentzen, M., and Kushnir, S. (2003). Arabidopsis phosphatidylglycerophosphate synthase 1 is essential for chloroplast differentiation, but is dispensable for mitochondrial function. Plant J. 33, 899-909. doi: 10.1046/j.1365-313X.2003. 01680.x

Baron, C. L., and Malhotra, V. (2002). Role of diacylglycerol in PKD recruitment to the TGN and protein transport to the plasma membrane. Science 295, 325-328. doi: 10.1126/science.1066759 (pollen-specific receptor-like kinase 6) and AtPRK2 (Zhang and McCormick, 2007; Duan et al., 2010; Chang et al., 2013; Takeuchi and Higashiyama, 2016). In this study, besides AtROP6, PG also bound to other ROP protein family members AtROP1 and AtROP3 in the liposome sedimentation assays and MST assay. It is required to further investigate how PG regulates AtROP1 and AtROP3 activity and participates in their cellular functions.

Lipids in plants play important regulatory functions in cellular activities more than just serving as building blocks for membrane structures, and the study to uncover membrane lipid-protein interaction would contribute to the understanding of lipids in the regulation of functional proteins in cellular activities.

\section{AUTHOR CONTRIBUTIONS}

$\mathrm{XH}, \mathrm{YY}$, and YG conceived and designed the research. $\mathrm{XH}$ prepared materials, conducted the research, and wrote the original manuscript. YS and GL participated in the preparing materials. YG revised the manuscript. All authors read and approved the final manuscript.

\section{FUNDING}

This work was supported by the National Natural Science Foundation of China (Grants 31430012, 31670260, U1706201), and National Genetically Modified Organisms Breeding Major Projects (2016ZX08009002).

\section{ACKNOWLEDGMENTS}

We thank Prof. Ying Fu for 35S::GFP-ROP6 seeds. We thank Prof. Deshu Lin for PIN2-GFP, rop $6^{\mathrm{CA}}$ and rop6-2 seeds.

\section{SUPPLEMENTARY MATERIAL}

The Supplementary Material for this article can be found online at: https://www.frontiersin.org/articles/10.3389/fpls.2018.00347/ full\#supplementary-material

Basu, D., Le, J., Zakharova, T., Mallery, E. L., and Szymanski, D. B. (2008) A SPIKE1 signaling complex controls actin-dependent cell morphogenesis through the heteromeric WAVE and ARP2/3 complexes. Proc. Natl. Acad. Sci. U.S.A. 105, 4044-4049. doi: 10.1073/pnas.0710294105

Bloch, D., Lavy, M., Efrat, Y., Efroni, I., Bracha-Drori, K., Abu-Abied, M., et al. (2005). Ectopic expression of an activated RAC in Arabidopsis disrupts membrane cycling. Mol. Biol. Cell 16, 1913-1927. doi: 10.1091/mbc.E04-070562

Bogdanov, M., Dowhan, W., and Vitrac, H. (2014). Lipids and topological rules governing membrane protein assembly. Biochim. Biophys. Acta 1843, 1475-1488. doi: 10.1016/j.bbamcr.2013.12.007

Bogdanov, M., Xie, J., and Dowhan, W. (2009). Lipid-protein interactions drive membrane protein topogenesis in accordance with the positive inside rule. J. Biol. Chem. 284, 9637-9641. doi: 10.1074/jbc.R800081200 
Chang, F., Gu, Y., Ma, H., and Yang, Z. (2013). AtPRK2 promotes ROP1 activation via RopGEFs in the control of polarized pollen tube growth. Mol. Plant 6, 1187-1201. doi: 10.1093/mp/sss103

Chen, M., Liu, H., Kong, J., Yang, Y., Zhang, N., Li, R., et al. (2011). RopGEF7 regulates PLETHORA-dependent maintenance of the root stem cell niche in Arabidopsis. Plant Cell 23, 2880-2894. doi: 10.1105/tpc.111. 085514

Chen, X., Grandont, L., Li, H., Hauschild, R., Paque, S., Abuzeineh, A., et al. (2014). Inhibition of cell expansion by rapid ABP1-mediated auxin effect on microtubules. Nature 516, 90-93. doi: 10.1038/nature13889

Chen, X., Irani, N. G., and Friml, J. (2011). Clathrin-mediated endocytosis: the gateway into plant cells. Curr. Opin. Plant Biol. 14, 674-682. doi: 10.1016/j.pbi. 2011.08.006

Chen, X., Naramoto, S., Robert, S., Tejos, R., Lofke, C., Lin, D., et al. (2012). ABP1 and ROP6 GTPase signaling regulate clathrin-mediated endocytosis in Arabidopsis roots. Curr. Biol. 22, 1326-1332. doi: 10.1016/j.cub.2012. 05.020

Chen, Y. H., Du, W., Hagemeijer, M. C., Takvorian, P. M., Pau, C., Cali, A., et al. (2015). Phosphatidylserine vesicles enable efficient en bloc transmission of enteroviruses. Cell 160, 619-630. doi: 10.1016/j.cell.2015.01.032

Coursol, S., Fan, L. M., Le Stunff, H., Spiegel, S., Gilroy, S., and Assmann, S. M. (2003). Sphingolipid signalling in Arabidopsis guard cells involves heterotrimeric G proteins. Nature 423, 651-654. doi: 10.1038/nature01643

Craddock, C., Lavagi, I., and Yang, Z. (2012). New insights into Rho signaling from plant ROP/Rac GTPases. Trends Cell Biol. 22, 492-501. doi: 10.1016/j.tcb.2012. 05.002

de Leeuw, E., te Kaat, K., Moser, C., Menestrina, G., Demel, R., de Kruijff, B., et al. (2000). Anionic phospholipids are involved in membrane association of FtsY and stimulate its GTPase activity. EMBO J. 19, 531-541. doi: 10.1093/emboj/19. 4.531

Del, V. K., and Stahelin, R. V. (2016). Using surface plasmon resonance to quantitatively assess lipid-protein interactions. Methods Mol. Biol. 1376, 141-153. doi: 10.1007/978-1-4939-3170-5_12

Dijkman, P. M., and Watts, A. (2015). Lipid modulation of early G proteincoupled receptor signalling events. Biochim. Biophys. Acta 1848, 2889-2897. doi: 10.1016/j.bbamem.2015.08.004

Domonkos, I., Malec, P., Sallai, A., Kovács, L., Itoh, K., Shen, G., et al. (2004). Phosphatidylglycerol is essential for oligomerization of photosystem I reaction center. Plant Physiol. 134, 1471-1478. doi: 10.1104/pp.103.037754

Dong, W., Lv, H., Xia, G., and Wang, M. (2012). Does diacylglycerol serve as a signaling molecule in plants? Plant Signal. Behav. 7, 472-475. doi: 10.4161/psb. 19644

Dowhan, W. (2017). Understanding phospholipid function: Why are there so many lipids? J. Biol. Chem. 292, 10755-10766. doi: 10.1074/jbc.X117.794891

Dowler, S., Kular, G., and Alessi, D. R. (2002). Protein lipid overlay assay. Sci. STKE 2002:pl6. doi: 10.1126/stke.2002.129.pl6

Drøbak, B. K., Watkins, P. A. C., Valenta, R., Dove, S. K., Lloyd, C. W., and Staiger, C. J. (1994). Inhibition of plant plasma membrane phosphoinositide phospholipase C by the actin-binding protein, profilin. Plant J. 6, 389-400. doi: 10.1046/j.1365-313X.1994.06030389.x

Duan, Q., Kita, D., Li, C., Cheung, A. Y., and Wu, H. M. (2010). FERONIA receptor-like kinase regulates RHO GTPase signaling of root hair development. Proc. Natl. Acad. Sci. U.S.A. 107, 17821-17826. doi: 10.1073/pnas.1005366107

Entzian, C., and Schubert, T. (2016). Studying small molecule-aptamer interactions using MicroScale Thermophoresis (MST). Methods 97, 27-34. doi: 10.1016/j. ymeth.2015.08.023

Fan, L., Li, R., Pan, J., Ding, Z., and Lin, J. (2015). Endocytosis and its regulation in plants. Trends Plant Sci. 20, 388-397. doi: 10.1016/j.tplants.2015.03.014

Fang, Y., Vilella-Bach, M., Bachmann, R., Flanigan, A., and Chen, J. (2001). Phosphatidic acid-mediated mitogenic activation of mTOR signaling. Science 294, 1942-1945. doi: 10.1126/science.1066015

Frentzen, M. (2004). Phosphatidylglycerol and sulfoquinovosyldiacylglycerol: anionic membrane lipids and phosphate regulation. Curr. Opin. Plant Biol. 7, 270-276. doi: 10.1016/j.pbi.2004.03.001

Fu, Y., Xu, T., Zhu, L., Wen, M., and Yang, Z. (2009). A ROP GTPase signaling pathway controls cortical microtubule ordering and cell expansion in Arabidopsis. Curr. Biol. 19, 1827-1832. doi: 10.1016/j.cub.2009.08.052
Gu, Y., Fu, Y., Dowd, P., Li, S., Vernoud, V., Gilroy, S., et al. (2005). A Rho family GTPase controls actin dynamics and tip growth via two counteracting downstream pathways in pollen tubes. J. Cell Biol. 169, 127-138. doi: 10.1083/ jcb.200409140

Gu, Y., Li, S., Lord, E. M., and Yang, Z. (2006). Members of a novel class of Arabidopsis Rho guanine nucleotide exchange factors control Rho GTPasedependent polar growth. Plant Cell 18, 366-381. doi: 10.1105/tpc.105.036434

Gu, Y., Vernoud, V., Fu, Y., and Yang, Z. (2003). ROP GTPase regulation of pollen tube growth through the dynamics of tip-localized F-actin. J. Exp. Bot. 54, 93-101. doi: 10.1093/jxb/erg035

Heilmann, I. (2016a). Phosphoinositide signaling in plant development. Development 143, 2044-2055. doi: 10.1242/dev.136432

Heilmann, I. (2016b). Plant phosphoinositide signaling - dynamics on demand. Biochim. Biophys. Acta 1861, 1345-1351. doi: 10.1016/j.bbalip.2016.02.013

Hsu, F.-F., Turk, J., Williams, T. D., and Welti, R. (2007). Electrospray ionization multiple stage quadrupole ion-trap and tandem quadrupole mass spectrometric studies on phosphatidylglycerol from Arabidopsis leaves. J. Am. Soc. Mass Spectr. 18, 783-790. doi: 10.1016/j.jasms.2006.12.012

Huang, J. B., Liu, H., Chen, M., Li, X., Wang, M., Yang, Y., et al. (2014). ROP3 GTPase contributes to polar auxin transport and auxin responses and is important for embryogenesis and seedling growth in Arabidopsis. Plant Cell 26, 3501-3518. doi: 10.1105/tpc.114.127902

Hwang, J. U., Gu, Y., Lee, Y. J., and Yang, Z. (2005). Oscillatory ROP GTPase activation leads the oscillatory polarized growth of pollen tubes. Mol. Biol. Cell 16, 5385-5399. doi: 10.1091/mbc.E05-05-0409

Hwang, J. U., Wu, G., Yan, A., Lee, Y. J., Grierson, C. S., and Yang, Z. (2010). Pollentube tip growth requires a balance of lateral propagation and global inhibition of Rho-family GTPase activity. J. Cell Sci. 123, 340-350. doi: 10.1242/jcs. 039180

Irani, N. G., and Russinova, E. (2009). Receptor endocytosis and signaling in plants. Curr. Opin. Plant Biol. 12, 653-659. doi: 10.1016/j.pbi.2009.09.011

Jouhet, J., Marechal, E., and Block, M. A. (2007). Glycerolipid transfer for the building of membranes in plant cells. Prog. Lipid Res. 46, 37-55. doi: 10.1016/j. plipres.2006.06.002

Ke, D., Fang, Q., Chen, C., Zhu, H., Chen, T., Chang, X., et al. (2012). The small GTPase ROP6 interacts with NFR5 and is involved in nodule formation in Lotus japonicus. Plant Physiol. 159, 131-143. doi: 10.1104/pp.112.197269

Kim, H. J., Jeong, M. H., Kim, K. R., Jung, C. Y., Lee, S. Y., Kim, H., et al. (2016). Protein arginine methylation facilitates KCNQ channel-PIP2 interaction leading to seizure suppression. eLife 5:e17159. doi: 10.7554/eLife. 17159

Kim, Y. J., Kim, J. E., Lee, J. H., Lee, M. H., Jung, H. W., Bahk, Y. Y., et al. (2004). The Vr-PLC3 gene encodes a putative plasma membrane-localized phosphoinositide-specific phospholipase $\mathrm{C}$ whose expression is induced by abiotic stress in mung bean (Vigna radiata L.). FEBS Lett. 556, 127-136. doi: 10.1016/S0014-5793(03)01388-7

Kobayashi, K., Endo, K., and Wada, H. (2016). Multiple impacts of loss of plastidic phosphatidylglycerol biosynthesis on photosynthesis during seedling growth of Arabidopsis. Front. Plant Sci. 7:336. doi: 10.3389/fpls.2016.00336

Kost, B., Lemichez, E., Spielhofer, P., Hong, Y., Tolias, K., Carpenter, C., et al. (1999). Rac homologues and compartmentalized phosphatidylinositol 4, 5bisphosphate act in a common pathway to regulate polar pollen tube growth. J. Cell Biol. 145, 317-330. doi: 10.1083/jcb.145.2.317

Lam, S. M., and Shui, G. H. (2013). Lipidomics as a principal tool for advancing biomedical research. J. Genet. Genomics 40, 375-390. doi: 10.1016/j.jgg.2013. 06.007

Lee, Y. J., Szumlanski, A., Nielsen, E., and Yang, Z. (2008). Rho-GTPase-dependent filamentous actin dynamics coordinate vesicle targeting and exocytosis during tip growth. J. Cell Biol. 181, 1155-1168. doi: 10.1083/jcb.200801086

Leeuwen, W. V., Okrész, L., Bögre, L., and Munnik, T. (2004). Learning the lipid language of plant signalling. Trends Plant Sci. 9, 378-384. doi: 10.1016/j.tplants. 2004.06.008

Lemmon, M. A. (2003). Phosphoinositide recognition domains. Traffic 4, 201-213. doi: 10.1034/j.1600-0854.2004.00071.x

Li, H., Lin, Y., Heath, R. M., Zhu, M. X., and Yang, Z. (1999). Control of pollen tube tip growth by a Rop GTPase-dependent pathway that leads to tip-localized calcium influx. Plant Cell 11, 1731-1742. 
Li, H., Wu, G., Ware, D., Davis, K. R., and Yang, Z. (1998). Arabidopsis Rho-related GTPases: differential gene expression in pollen and polar localization in fission yeast. Plant Physiol. 118, 407-417. doi: 10.1104/pp.118.2.407

Li, N., Xu, C., Li-Beisson, Y., and Philippar, K. (2016). Fatty acid and lipid transport in plant cells. Trends Plant Sci. 21, 145-158. doi: 10.1016/j.tplants.2015.10.011

Li, S., Gu, Y., Yan, A., Lord, E., and Yang, Z. B. (2008). RIP1 (ROP Interactive Partner 1)/ICR1 marks pollen germination sites and may act in the ROP1 pathway in the control of polarized pollen growth. Mol. Plant 1, 1021-1035. doi: $10.1093 / \mathrm{mp} / \mathrm{ssn} 051$

Li, Y., Beisson, F., Ohlrogge, J., and Pollard, M. (2007). Monoacylglycerols are components of root waxes and can be produced in the aerial cuticle by ectopic expression of a suberin-associated acyltransferase. Plant Physiol. 144, 1267-1277. doi: 10.1104/pp.107.099432

Lin, C. C., Melo, F. A., Ghosh, R., Suen, K. M., Stagg, L. J., Kirkpatrick, J., et al. (2012). Inhibition of basal FGF receptor signaling by dimeric Grb2. Cell 149, 1514-1524. doi: 10.1016/j.cell.2012.04.033

Lin, D., Cao, L., Zhou, Z., Zhu, L., Ehrhardt, D., Yang, Z., et al. (2013). Rho GTPase signaling activates microtubule severing to promote microtubule ordering in Arabidopsis. Curr. Biol. 23, 290-297. doi: 10.1016/j.cub.2013.01.022

Lin, D., Nagawa, S., Chen, J., Cao, L., Chen, X., Xu, T., et al. (2012). A ROP GTPasedependent auxin signaling pathway regulates the subcellular distribution of PIN2 in Arabidopsis roots. Curr. Biol. 22, 1319-1325. doi: 10.1016/j.cub.2012. 05.019

Lin, D., Ren, H., and Fu, Y. (2015). ROP GTPase-mediated auxin signaling regulates pavement cell interdigitation in Arabidopsis thaliana. J. Integr. Plant Biol. 57, 31-39. doi: 10.1111/jipb.12281

Luo, N., Yan, A., Liu, G., Guo, J., Rong, D., Kanaoka, M. M., et al. (2017). Exocytosis-coordinated mechanisms for tip growth underlie pollen tube growth guidance. Nat. Commun. 8:1687. doi: 10.1038/s41467-017-01452-0

Maekawa, M., and Fairn, G. D. (2014). Molecular probes to visualize the location, organization and dynamics of lipids. J. Cell Sci. 127, 4801-4812. doi: 10.1242/ jcs. 150524

Mandal, M. K., Chandra-Shekara, A. C., Jeong, R. D., Yu, K., Zhu, S., Chanda, B., et al. (2012). Oleic acid-dependent modulation of NITRIC OXIDE ASSOCIATED1 protein levels regulates nitric oxide-mediated defense signaling in Arabidopsis. Plant Cell 24, 1654-1674. doi: 10.1105/tpc.112.096768

Manoharan, K., Prasad, R., and Guha-Mukherjee, S. (1985). Greening-related lipid changes in leaves, protoplasts and a plasmamembrane-enriched fraction of pea. Phytochemistry 24, 431-433. doi: 10.1016/S0031-9422(00)80741-4

Milne, S. B., Ivanova, P. T., DeCamp, D., Hsueh, R. C., and Brown, H. A. (2005). A targeted mass spectrometric analysis of phosphatidylinositol phosphate species. J. Lipid Res. 46, 1796-1802. doi: 10.1194/jlr.D500010-JLR200

Miyawaki, K. N., and Yang, Z. (2014). Extracellular signals and receptor-like kinases regulating ROP GTPases in plants. Front. Plant Sci. 5:449. doi: 10.3389/fpls. 2014.00449

Moreau, P., Bessoule, J. J., Mongrand, S., Testet, E., Vincent, P., and Cassagne, C. (1998). Lipid trafficking in plant cells. Prog. Lipid Res. 37, 371-391. doi: 10.1016/ S0163-7827(98)00016-2

Munnik, T. (2001). Phosphatidic acid: an emerging plant lipid second messenger. Trends Plant Sci. 6, 227-233. doi: 10.1016/S1360-1385(01)01918-5

Munnik, T., and Wierzchowiecka, M. (2013). Lipid-binding analysis using a fat blot assay. Methods Mol. Biol. 1009, 253-259. doi: 10.1007/978-1-62703-401-2_23

Nagawa, S., Xu, T., Lin, D., Dhonukshe, P., Zhang, X., Friml, J., et al. (2012). ROP GTPase-dependent actin microfilaments promote PIN1 polarization by localized inhibition of clathrin-dependent endocytosis. PLoS Biol. 10:e1001299. doi: 10.1371/journal.pbio.1001299

Ng, C. K., Carr, K., McAinsh, M. R., Powell, B., and Hetherington, A. M. (2001). Drought-induced guard cell signal transduction involves sphingosine1-phosphate. Nature 410, 596-599. doi: 10.1038/35069092

Paciorek, T., Zazimalova, E., Ruthardt, N., Petrasek, J., Stierhof, Y. D., KleineVehn, J., et al. (2005). Auxin inhibits endocytosis and promotes its own efflux from cells. Nature 435, 1251-1256. doi: 10.1038/nature03633

Pan, J., Fujioka, S., Peng, J., Chen, J., Li, G., and Chen, R. (2009). The E3 ubiquitin ligase SCFTIR1/AFB and membrane sterols play key roles in auxin regulation of endocytosis, recycling, and plasma membrane accumulation of the auxin efflux transporter PIN2 in Arabidopsis thaliana. Plant Cell 21, 568-580. doi: $10.1105 /$ tpc.108.061465
Peer, W. A. (2013). From perception to attenuation: auxin signalling and responses. Curr. Opin. Plant Biol. 16, 561-568. doi: 10.1016/j.pbi.2013.08.003

Poraty-Gavra, L., Zimmermann, P., Haigis, S., Bednarek, P., Hazak, O., Stelmakh, O. R., et al. (2013). The Arabidopsis Rho of plants GTPase AtROP6 functions in developmental and pathogen response pathways. Plant Physiol. 161, 1172-1188. doi: 10.1104/pp.112.213165

Ren, H., Dang, X., Yang, Y., Huang, D., Liu, M., Gao, X., et al. (2016). SPIKE1 activates ROP GTPase to modulate petal growth and shape. Plant Physiol. 172, 358-371. doi: 10.1104/pp.16.00788

Rigal, A., Doyle, S. M., and Robert, S. (2015). Live cell imaging of FM4-64, a tool for tracing the endocytic pathways in Arabidopsis root cells. Methods Mol. Biol. 1242, 93-103. doi: 10.1007/978-1-4939-1902-4_9

Ritter, D., and Yopp, J. H. (1993). Plasma membrane lipid composition of the halophilic cyanobacterium Aphanothece halophytica. Arch. Microbiol. 159, 435-439. doi: 10.1007/BF00288590

Sheen, J. (2001). Signal transduction in maize and Arabidopsis mesophyll protoplasts. Plant Physiol. 127, 1466-1475. doi: 10.1104/pp.010820

Simon, M. L., Platre, M. P., Assil, S., van Wijk, R., Chen, W. Y., Chory, J., et al. (2014). A multi-colour/multi-affinity marker set to visualize phosphoinositide dynamics in Arabidopsis. Plant J. 77, 322-337. doi: 10.1111/tpj.12358

Sorek, N., Segev, O., Gutman, O., Bar, E., Richter, S., Poraty, L., et al. (2010). An S-acylation switch of conserved $\mathrm{G}$ domain cysteines is required for polarity signaling by ROP GTPases. Curr. Biol. 20, 914-920. doi: 10.1016/j.cub.2010. 03.057

Stockle, D., Herrmann, A., Lipka, E., Lauster, T., Gavidia, R., Zimmermann, S., et al. (2016). Putative RopGAPs impact division plane selection and interact with kinesin-12 POK1. Nat. Plants 2:16120. doi: 10.1038/nplants.2016.120

Suh, B. C., and Hille, B. (2008). PIP2 is a necessary cofactor for ion channel function: how and why? Annu. Rev. Biophys. 37, 175-195. doi: 10.1146/annurev. biophys.37.032807.125859

Sun, F., Kale, S. D., Azurmendi, H. F., Li, D., Tyler, B. M., and Capelluto, D. G. (2013). Structural basis for interactions of the Phytophthora sojae RxLR effector Avh5 with phosphatidylinositol 3-phosphate and for host cell entry. Mol. Plant Microbe Interact. 26, 330-344. doi: 10.1094/MPMI-07-120184-R

Swamy, M. J., and Sankhala, R. S. (2013). Probing the Thermodynamics of Proteinlipid Interactions by Isothermal Titration Calorimetry. New York City, NY: Humana Press. doi: 10.1007/978-1-62703-275-9_3

Takeuchi, H., and Higashiyama, T. (2016). Tip-localized receptors control pollen tube growth and LURE sensing in Arabidopsis. Nature 531, 245-248. doi: 10. 1038 /nature17413

Tejos, R., Sauer, M., Vanneste, S., Palacios-Gomez, M., Li, H., Heilmann, M., et al. (2014). Bipolar plasma membrane distribution of phosphoinositides and their requirement for auxin-mediated cell polarity and patterning in Arabidopsis. Plant Cell 26, 2114-2128. doi: 10.1105/tpc.114.126185

Venus, Y., and Oelmuller, R. (2013). Arabidopsis ROP1 and ROP6 influence germination time, root morphology, the formation of F-actin bundles, and symbiotic fungal interactions. Mol. Plant 6, 872-886. doi: 10.1093/mp/sss101

Wang, C., Hu, T., Yan, X., Meng, T., Wang, Y., Wang, Q., et al. (2016). Differential regulation of clathrin and its adaptor proteins during membrane recruitment for endocytosis. Plant Physiol. 171, 215-229. doi: 10.1104/pp.15.01716

Wang, C., Xu, X., Hong, Z., Feng, Y., and Zhang, Z. (2015a). Involvement of ROP6 and clathrin in nodulation factor signaling. Plant Signal. Behav. 10:e1033127. doi: 10.1080/15592324.2015.1033127

Wang, C., Yan, X., Chen, Q., Jiang, N., Fu, W., Ma, B., et al. (2013). Clathrin light chains regulate clathrin-mediated trafficking, auxin signaling, and development in Arabidopsis. Plant Cell 25, 499-516. doi: 10.1105/tpc.112.108373

Wang, C., Zhu, M., Duan, L., Yu, H., Chang, X., Li, L., et al. (2015b). Lotus japonicus clathrin heavy Chain 1 is associated with Rho-Like GTPase ROP6 and involved in nodule formation. Plant Physiol. 167, 1497-1510. doi: 10.1104/pp.114. 256107

Wang, Y., Zhang, W. Z., Song, L. F., Zou, J. J., Su, Z., and Wu, W. H. (2008). Transcriptome analyses show changes in gene expression to accompany pollen germination and tube growth in Arabidopsis. Plant Physiol. 148, 1201-1211. doi: $10.1104 /$ pp.108.126375

Xu, T. (2012). Rho GTPase activity analysis in plant cells. Methods Mol. Biol. 876, 135-144. doi: 10.1007/978-1-61779-809-2_10 
Xu, T., Wen, M., Nagawa, S., Fu, Y., Chen, J. G., Wu, M. J., et al. (2010). Cell surface- and rho GTPase-based auxin signaling controls cellular interdigitation in Arabidopsis. Cell 143, 99-110. doi: 10.1016/j.cell.2010.09.003

Yang, W., Pollard, M., Li-Beisson, Y., Beisson, F., Feig, M., and Ohlrogge, J. (2010). A distinct type of glycerol-3-phosphate acyltransferase with sn-2 preference and phosphatase activity producing 2-monoacylglycerol. Proc. Natl. Acad. Sci. U.S.A. 107, 12040-12045. doi: 10.1073/pnas.0914149107

Young, B. P., Shin, J. J., Orij, R., Chao, J. T., Li, S. C., Guan, X. L., et al. (2010). Phosphatidic acid is a $\mathrm{pH}$ biosensor that links membrane biogenesis to metabolism. Science 329, 1085-1088. doi: 10.1126/science.1191026

Yu, F., Qian, L., Nibau, C., Duan, Q., Kita, D., Levasseur, K., et al. (2012). FERONIA receptor kinase pathway suppresses abscisic acid signaling in Arabidopsis by activating ABI2 phosphatase. Proc. Natl. Acad. Sci. U.S.A. 109, 14693-14698. doi: 10.1073/pnas.1212547109

Yu, L., Nie, J., Cao, C., Jin, Y., Yan, M., Wang, F., et al. (2010). Phosphatidic acid mediates salt stress response by regulation of MPK6 in Arabidopsis thaliana. New Phytol. 188, 762-773. doi: 10.1111/j.1469-8137.2010.03422.x

Yuan, X., Li, Y., Liu, S., Xia, F., Li, X., and Qi, B. (2014). Accumulation of eicosapolyenoic acids enhances sensitivity to abscisic acid and mitigates the effects of drought in transgenic Arabidopsis thaliana. J. Exp. Bot. 65, 1637-1649. doi: 10.1093/jxb/eru031

Zhang, Q., Lin, F., Mao, T., Nie, J., Yan, M., Yuan, M., et al. (2012). Phosphatidic acid regulates microtubule organization by interacting with MAP65-1 in response to salt stress in Arabidopsis. Plant Cell 24, 4555-4576. doi: 10.1105/ tpc. 112.104182

Zhang, W., Qin, C., Zhao, J., and Wang, X. (2004). Phospholipase D alpha 1derived phosphatidic acid interacts with $\mathrm{ABI} 1$ phosphatase $2 \mathrm{C}$ and regulates abscisic acid signaling. Proc. Natl. Acad. Sci. U.S.A. 101, 9508-9513. doi: 10 1073/pnas.0402112101

Zhang, Y., and McCormick, S. (2007). A distinct mechanism regulating a pollen-specific guanine nucleotide exchange factor for the small GTPase Rop in Arabidopsis thaliana. Proc. Natl. Acad. Sci. U.S.A. 104, 18830-18835. doi: 10.1073/pnas.0705874104

Zhang, Z., Yang, F., Na, R., Zhang, X., Yang, S., Gao, J., et al. (2014). AtROP1 negatively regulates potato resistance to Phytophthora infestans via NADPH oxidase-mediated accumulation of $\mathrm{H}_{2} \mathrm{O}_{2}$. BMC Plant Biol. 14:392. doi: 10.1186/ s12870-014-0392-2

Zhao, S., Jiang, Y., Zhao, Y., Huang, S., Yuan, M., Zhao, Y., et al. (2016). CASEIN KINASE1-LIKE PROTEIN2 regulates actin filament stability and stomatal closure via phosphorylation of actin depolymerizing factor. Plant Cell 28, 1422-1439. doi: 10.1105/tpc.16. 00078

Conflict of Interest Statement: The authors declare that the research was conducted in the absence of any commercial or financial relationships that could be construed as a potential conflict of interest.

Copyright (c) 2018 Han, Shi, Liu, Guo and Yang. This is an open-access article distributed under the terms of the Creative Commons Attribution License (CC BY). The use, distribution or reproduction in other forums is permitted, provided the original author(s) and the copyright owner are credited and that the original publication in this journal is cited, in accordance with accepted academic practice. No use, distribution or reproduction is permitted which does not comply with these terms. 